\title{
Monetary Unification and the Price of Risk: An Unconditional Analysis.
}

\author{
Hans Dewachter ${ }^{a, b}$, Konstantijn Maes $^{a}$ and Kristien Smedts ${ }^{a *}$ \\ ${ }^{a}$ CES, Catholic University of Leuven \\ ${ }^{b}$ RIFM, Erasmus University Rotterdam
}

January 30, 2002

\begin{abstract}
In this paper we assess the effects of monetary unification in Europe on the pricing behavior in financial markets and more in particular on excess returns. We use the standard IAPT framework to analyze the role of the exchange rate in separating excess return pricing across European countries. We find that, already in the decade prior to EMU, exchange rate changes do not (unconditionally) correlate strongly with financial market movements across countries. Consequently elimination of exchange rate variability through monetary unification is not likely to have had major implications for pricing behavior in EMU markets.
\end{abstract}

${ }^{*}$ Corresponding author. Address for correspondence: CES, Naamsestraat 69, B-3000 Leuven. Email Kristien.Smedts@econ.kuleuven.ac.be, tel: (+) 32 (0)16 326839. Both Kristien Smedts and Konstantijn Maes are Aspirant of the FWO-Vlaanderen. 


\section{Introduction}

At the beginning of 1999 the Euro was introduced and it replaced the national currencies in twelve European Union (EU) member states. Despite the fact that the introduction of the Euro is only one step in the complete process of economic and monetary integration, it will most likely act as an important catalyst for further development and integration in the Euro area. Undoubtedly, this integration process already had, and will have in the future, wide ranging implications for European financial markets. One of these implications is the integration in the money markets and the bond markets. This process is rather transparent, as money market rates (cf. Euribor rates that replaced national interbank offered rates) are equalized and bond market yields are converging across the different member states. Another possible implication is the integration of the stock markets. In the past decade, legislative measures have been taken to harmonize the regulatory structure and stock exchanges have set up initiatives -with mixed success- to create a market with pan-European dimensions. ${ }^{1}$ The integration process is indeed hampered by legal barriers, informational assymetries and investment restrictions.

In the light of this changing environment there are economic motivations, both for investors as for corporate managers, to get a clearer idea of the stance of financial integration in the Euro area. An important motivation concerns the identification and interpretation of the market prices of risk in the different European Monetary Union (EMU) member states and the potential impact of the integration process on the diversification strategies. Diversification is beneficial independent of whether EMU is integrated or not, as a wider range of assets will most likely give opportunities to diversify away some domestic risk factors. However, the kind of diversification will differ depending on whether EMU is integrated or not. If the national stock markets behave like an integrated market, then country level diversification benefits will decrease and EMU-wide sector based asset allocation strategies will possibly display a superior risk-adjusted performance. Investors may therefore want to switch portfolio compositions. For corporate managers, an important issue concerns corporate financial decisions and capital budget decisions as the cost of capital may or may not differ across countries.

A key problem in the studies of integration versus segmentation is the definition and its empirical counterpart of the notion of financial integration. In the existing literature, one can distinguish three broad approaches to examine the integration issue. The first approach assumes that integration between financial markets can be examined by looking at the correlation structure between the market returns. In this methodology, capital market integration is in fact judged on the basis of economic integration. However, following Adler and Dumas (1983) the covariance matrix says nothing about the presence or absence of segmentation. It merely says something about the existing linkages -of any kind- between different countries. Often, high correlation and integration go hand in hand, but this needs not be the case. Output mixes vary considerably across countries, partly because of the specialization

\footnotetext{
${ }^{1}$ Licht (1997) gives an overview of the regulatory and legislative measures taken by the European commission and national governments, and the projects undertaken by the stock exchanges to integrate their markets.
} 
induced by international trade. ${ }^{2}$ Random shocks which affect specific industrial sectors may therefore have a relatively large impact on those stock markets where these sectors are large, but not on other stock markets. This makes clear that small correlations between different stock market indices can be consistent with perfect capital market integration. Alternatively, a second approach focuses on investment restrictions as an indicator of integration. Segmentation can be the result of a number of barriers and imperfections, which can be classified into legal barriers and informational barriers. It is however insufficient to assess the degree of integration or segmentation solely based on such imperfections. A number of restrictions is difficult to interpret, and the importance of the barriers is often different across different countries. Moreover, investment restrictions may not be binding, as investors are innovative to get around investment controls (see Bekaert and Harvey (1995), and Jorion and Schwartz (1986)). A last class of integration studies focuses on the restrictions imposed by any asset pricing model (e.g. CAPM, CCAPM, APT) on the pricing of assets. In this literature, integration is defined as the situation where assets in various national markets are traded as though their prices are determined in a unified market, so as to yield the same risk-adjusted expected returns, irrespective of the currency of denomination, and given a particular model for the pricing of risk. This makes clear that these tests are always joint tests of the model being valid, markets being efficient and markets being integrated. (see Cho, Eun and Senbet (1986), Korajczyk and Viallet (1989), Bekaert and Hodrick (1992), Jorion, (1992), Stulz (1994), Hardouvelis, Malliaropulos and Priestley (1999), Naranjo and Proropapadakis (1997) among others).

In this paper, we use the international asset pricing theory (IAPT) methodology to empirically assess the implications of monetary unification on financial markets for various EMU member states. Monetary unification is likely to have (had) macro effects on financial markets because of the removal of exchange rate variability. In fact, according to the IAPT, exchange rate variability is crucial in converting foreign pricing kernels to the domestic currency denominated pricing kernels. Or more in particular, exchange rate operations ensure that no arbitrage opportunities can arise between domestic and foreign investment opportunities by pricing foreign assets at domestic prices of risk and domestic interest rates. By removing exchange rate variability, monetary unification can excert large effects on financial markets by (i) imposing an identical monetary policy on the member states and by (ii) creating one common currency market with identical price of risk behavior. Assessing the likely macro effects of monetary unification thus boils down to assessing the role of exchange rate variability for financial integration in EMU. In this paper, we basically assess the role of the exchange rate markets in generating a financial integration across European countries. We study this exchange rate role from various currency perspectives on global market indices, including the most important bond market and stock market indices.

We proceed as follows. First, in section 2 we set out the standard IAPT framework and make explicit the crucial conversion role of the exchange rate in financially integrated markets.

\footnotetext{
${ }^{2}$ Rose and Engel (2000) argue that members of curreny unions are more specialised, compared to sovereign countries, and therefore, the former countries are potentially more vulnerable to asymmetric industry shocks.
} 
In section 3 we test for financial integration on excess returns. More in particular we test whether or not arbitrage opportunities exist between domestic and foreign investments in terms of excess returns. We do this analysis from various domestic currency perspectives. As a result of these tests, we find a number of currency dependent prices of risk (pricing kernels). We then proceed by testing for the role of the exchange rate variability by testing for significant differences across these currency specific prices of risk. Equality of these prices of risk would imply that the exchange rate does not crucially affect the financial markets and hence that monetary unification (removing this non-essential exchange rate variability) is unlikely to have major implications on financial markets. To anticipate the results, the (unconditional) tests reported in this section actually cannot reject the equality and hence suggest that the monetary unification is (was) not likely to generate immediate macro pricing effects. Finally section 4 concludes.

The paper is organized as follows. In section 2, we present the asset pricing framework in which the notion of financial integration will be investigated. Section 3 presents the estimation methodology and studies empirically the degree of financial integration between several EMU member states vis-à-vis Non-EMU member states. Finally section 4 concludes.

\section{The Arbitrage Pricing Model}

In this section we set out both the theoretical as well as the empirical framework that we use in the empirical analysis. This section first gives a brief continuous time theory of what our definition of integration implies in terms of IAPT and subsequently recasts this setting to the more practical discrete time approximation. Finally, we briefly explain the estimation approach we use in order to test for financial integration from an unconditional point of view.

\subsection{IAPT and integration}

As noted in the introduction, there is a variety of ways to measure financial integration and each of these methods, obviously, implies a somewhat different meaning of financial integration. In this paper we follow Stulz (1981) by defining financial integration as a situation in which markets basically price risk as if they would be priced in one and the same market. The crucial aspect of the definition is how one defines a market. Here, the most stringent definition of a market one can take is in terms of currency denomination. That is we define a market as a place where the currency denomination of assets is identical. This definition hence brings us to the concept of integration stating that financial integration across markets means that assets of different local currency denominations, but converted to a single common currency, are priced as if currency denomination is identical and thus can be considered as if priced in a single financial market. A second definition of integration is even stronger, stating that whatever the currency denomination, markets price assets as if priced in a single financial market. As is shown below, this last idea can be made operational by imposing zero covariance of exchange rate changes with asset holding returns in the different financial 
markets.

To formalize the above statements, we follow Solnik (1983) extending the standard APT model of Ross (1976) to an international setting where the exchange rate is spanned by the asset market risk alone. Consider $m=1, \ldots, M$ economies and correspondingly $m=1, \ldots, M$ currencies $^{3}$, with $n=1, \ldots, N$ assets per country. Denote $P_{n}^{m_{1}}$ the price of risky asset $n$ of country $m_{1}$ expressed in currency $m_{1}$ and an analogous representation in the country $m_{2}$ with asset prices $P_{n}^{m_{2}}$. A starting assumption of the IAPT model is that investors of different countries have homogenous beliefs on the dynamics governing asset prices. Asset prices are supposed to be driven by some international factors (risks) and some idiosyncratic shocks as well. International factors are represented by $K$ Wiener processes $W_{k}(t), k=1, \ldots, K$ while idiosyncratic components are denoted by $Z^{P_{n}^{m_{1}}}(t)$ and $Z^{P_{n}^{m_{2}}}(t)$ for the $m_{1}$ and $m_{2}$ country respectively. The dynamics of local currency denominated prices is supposed to be given by following equations:

$$
\begin{aligned}
& \frac{d P_{n}^{m_{1}}}{P_{n}^{m_{1}}}=\mu_{n}^{m_{1}}(t) d t+\sum_{k=1}^{K} L_{n, k}^{m_{1}} d W_{k}(t)+\sigma^{P_{n}^{m_{1}}} d Z^{P_{n}^{m_{1}}}(t) \\
& \frac{d P_{n}^{m_{2}}}{P_{n}^{m_{2}}}=\mu_{n}^{m_{2}}(t) d t+\sum_{k=1}^{K} L_{n, k}^{m_{2}} d W_{k}(t)+\sigma^{P_{n}^{m_{2}}} d Z^{P_{n}^{m_{2}}}(t)
\end{aligned}
$$

In this setting, $\mu_{n}^{m_{1}}=E\left(\frac{d P_{n}^{m_{1}}}{P_{n}^{m_{1}}}\right)$ denotes the expected instantaneous holding return on the asset and $L_{n, k}^{m_{1}}$ represents the loading of asset $n$ in country $m_{1}$ to the risk $k$. Since $d Z^{P_{n}^{m_{1}}}$ and $d Z^{P_{n}^{m_{2}}}$ denote idiosyncratic shocks in the asset prices, it will not be priced in a sufficiently large economy. Hence, following standard $\mathrm{APT}^{4}$ we have that:

$$
\begin{aligned}
& \mu_{n}^{m_{1}}(t) d t=r^{m_{1}}(t) d t+\sum_{k=1}^{K} \lambda_{k}^{m_{1}} L_{n, k}^{m_{1}} d t \\
& \mu_{n}^{m_{2}}(t) d t=r^{m_{2}}(t) d t+\sum_{k=1}^{K} \lambda_{k}^{m_{2}} L_{n, k}^{m_{2}} d t
\end{aligned}
$$

where $\lambda_{k}^{m_{1}}$ and $\lambda_{k}^{m_{2}}$ denote the country $m_{1}$ and $m_{2}$ unit prices of risk for risk source $k$ and $r^{m_{1}}(t)$ and $r^{m_{2}}(t)$ denote the instantaneously riskless interest rates. Excess returns are therefore fully explained by the amount of risk taken in the specific investment under consideration.

Every investor only cares about home currency denominated returns. In an international investment strategy one thus takes into account the exchange rate changes. In terms of the

\footnotetext{
${ }^{3}$ If we want to refer explicitely to two different currencies, we denote them as $m_{1}$ and $m_{2}$. If we want to refer to just some currency denomination, we denote it as $m$.

${ }^{4}$ (I)APT only provides an approximate relation for expected asset returns. One needs to impose additional structure, so that the approximation becomes exact. See for instance Huberman and Kandel (1987).
} 
analysis above, an investor with local currency $m_{1}$ will convert currency $m_{2}$ proceeds to currency $m_{1}$ proceeds. Therefore, we introduce the exchange rate dynamics where we define the exchange rate $S_{m_{1}}^{m_{2}}(t)$ as the unit price of $m_{2}$ currency in terms of $m_{1}$ currency:

$$
\frac{d S_{m_{1}}^{m_{2}}(t)}{S_{m_{1}}^{m_{2}}(t)}=\mu^{S_{m_{1}}^{m_{2}}}(t) d t+\sum_{k=1}^{K} L_{k}^{S_{m_{1}}^{m_{2}}} d W_{k}(t)+\sigma^{S_{m_{1}}^{m_{2}}} d Z^{S_{m_{1}}^{m_{2}}}(t)
$$

with $L_{k}^{S_{m_{1}}^{m_{2}}}$ is the loading of the exchange rate to the risk $k$ and $\mu^{S_{m_{1}}^{m_{2}}}(t)$ the expected instantaneous holding return of the exchange rate. This definition of the exchange rate implies that exchange rate fluctuations follow the same factor structure as asset returns. Other exchange risk -the idiosyncratic component- can be diversified away and will thus not be priced. This is a crucial assumption for the analysis here below to hold. Using Ito's lemma it is standard to derive the dynamics of an investment in an asset of country $m_{2}$ denominated in $m_{1}$ currency. For notational ease we define the $m_{1}$ currency value dynamics of an investment in the asset $P_{n}^{m_{2}}$ by $V_{n}^{m_{1}}(t) \equiv S_{m_{1}}^{m_{2}}(t) \cdot P_{n}^{m_{2}}(t)$ :

$$
\frac{d V_{n}^{m_{1}}(t)}{V_{n}^{m_{1}}(t)}=\frac{d P_{n}^{m_{2}}(t)}{P_{n}^{m_{2}}(t)}+\frac{d S_{m_{1}}^{m_{2}}(t)}{S_{m_{1}}^{m_{2}}(t)}+\frac{d P_{n}^{m_{2}}(t)}{P_{n}^{m_{2}}(t)} \frac{d S_{m_{1}}^{m_{2}}(t)}{S_{m_{1}}^{m_{2}}(t)}
$$

Substituting in (6) the dynamics for $\frac{d P_{n}^{m_{2}}(t)}{P_{n}^{m_{2}}(t)}$ and $\frac{d S_{m_{1}}^{m_{2}}(t)}{S_{m_{1}}^{m_{2}}(t)}$ gives:

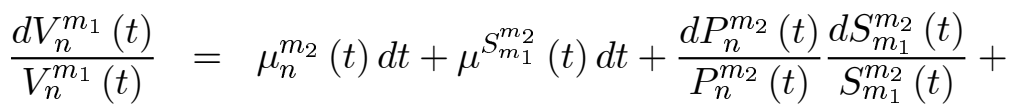

$$
\begin{aligned}
& +\sum_{k=1}^{K}\left(L_{n, k}^{m_{2}}+L_{k}^{S_{m_{1}}^{m_{2}}}\right) d W_{k}(t)+\sigma^{P_{n}^{m_{2}}} d Z^{P_{n}^{m_{2}}}(t)+\sigma^{S_{m_{1}}^{m_{2}}} d Z^{S_{m_{1}}^{m_{2}}}(t) \\
& \frac{d V_{n}^{m_{1}}(t)}{V_{n}^{m_{1}}(t)}=E\left(\frac{d V_{n}^{m_{1}}(t)}{V_{n}^{m_{1}}(t)}\right)+\sum_{k=1}^{K}\left(L_{n, k}^{m_{2}}+L_{k}^{S_{m_{1}}^{m_{2}}}\right) d W_{k}(t)+\sigma^{V_{n}^{m_{1}}} d Z^{V_{n}^{m_{1}}}(t)
\end{aligned}
$$

where

$$
\begin{aligned}
& E\left(\frac{d V_{n}^{m_{1}}(t)}{V_{n}^{m_{1}}(t)}\right)=\mu_{n}^{m_{2}}(t) d t+\mu^{S_{m_{1}}^{m_{2}}}(t) d t+\frac{d P_{n}^{m_{2}}(t)}{P_{n}^{m_{2}}(t)} \frac{d S_{m_{1}}^{m_{2}}(t)}{S_{m_{1}}^{m_{2}}(t)} \\
& \sigma^{V_{n}^{m_{1}}} d Z^{V_{n}^{m_{1}}}(t)=\sigma^{P_{n}^{m_{2}}} d Z^{P_{n}^{m_{2}}}(t)+\sigma^{S_{m_{1}}^{m_{2}}} d Z^{S_{m_{1}}^{m_{2}}}(t)
\end{aligned}
$$

The pricing relation now becomes:

$$
E\left(\frac{d V_{n}^{m_{1}}(t)}{V_{n}^{m_{1}}(t)}\right)=r^{m_{1}}(t) d t+\sum_{k=1}^{K} \lambda_{k}^{m_{1}}\left(L_{n, k}^{m_{2}}+L_{k}^{S_{m_{1}}^{m_{2}}}\right) d t
$$

This shows that the risk premium for an international investment strategy is in fact a total risk premium, i.e. common risk in local currency plus exchange risk, evaluated at the home market price of risk. When this last relationship breaks down, that is, foreign currency returns are not evaluated at the home currency market prices of risk, we can conclude that 
the markets under consideration are not finacially integrated. Finally, note that this last relationship determines the drift of the exchange rate dynamics as follows:

$$
\mu^{S_{m_{1}}^{m_{2}}}(t) d t=\left(r^{m_{1}}(t)-r^{m_{2}}(t)\right) d t+\sum_{k=1}^{K} \lambda_{k}^{m_{1}} L_{k}^{S_{m_{1}}^{m_{2}}} d t
$$

Thus the expected exchange rate return equals the instantenous interest rate differential augmented with the risk premium on the exchange rate.

It is important to note that each investor is always stuck with his own market prices of risk. In a financially integrated market, these market prices of risk are however linked to each other by the exchange rate dynamics. More in particular, we will show that market prices of risk are converted from one currency denomination to the other through the exchange rate dynamics. Following the law of one price, a domestic investment and an equivalent -with the same (total) factor risk- foreign investment should in principle sell at the same price. This absence of arbitrage opportunities can be guaranteed only by restricting exchange rate dynamics. To show this, we construct a standard arbitrage scheme. More specifically, consider buying the foreign asset $P_{n}^{m_{2}}$ with factor loadings $L_{k}^{m_{2}}, k=1, \ldots, K$, converted to home currency $\left(\frac{d V_{n}^{m_{1}}(t)}{V_{n}^{m_{1}}(t)}\right)$ (see equation (6)). Denote the (equivalent) domestic investment with total factor risks given by $\left(L_{k}^{m_{2}}+L^{S_{m_{1}}^{m_{2}}}\right)$ by $P_{n}^{m_{1}}(t)$. Domestic no-arbitrage conditions imply that the expected return of this asset is given by:

$$
E\left(\frac{d P_{n}^{m_{1}}(t)}{P_{n}^{m_{1}}(t)}\right)=r^{m_{1}}(t) d t+\sum_{k=1}^{K} \lambda_{k}^{m_{1}}\left(L_{k}^{m_{2}}+L^{S_{m_{1}}^{m_{2}}}\right) d t .
$$

Imposing the no-arbitrage condition between an equivalent domestic and foreign investment now brings forward the role played by the exchange rate variability. More specifically, the law of one price imposes equality of expected returns:

$$
E\left(\frac{d P_{n}^{m_{1}}(t)}{P_{n}^{m_{1}}(t)}\right)=E\left(\frac{d V_{n}^{m_{1}}(t)}{V_{n}^{m_{1}}(t)}\right)
$$

Using equations (11), (10) and (8), this can be simplified to:

$$
\sum_{k=1}^{K} \lambda_{k}^{m_{1}}\left(L_{k}^{m_{2}}+L^{S_{m_{1}}^{m_{2}}}\right) d t=\sum_{k=1}^{K} \lambda_{k}^{m_{2}} L_{n, k}^{m_{2}} d t+\frac{d P_{n}^{m_{2}}(t)}{P_{n}^{m_{2}}(t)} \frac{d S_{m_{1}}^{m_{2}}(t)}{S_{m_{1}}^{m_{2}}(t)}
$$

Given the international nature of the arbitrage scheme it is obvious that arbitrage opportunities are eliminated through exchange rate adjustments. More in particular, it is easy to show that the exchange rate dynamics, consistent with absence of arbitrage, are uniquely determined by the following factor sensitivity specification:

$$
L_{k}^{S_{m_{1}}^{m_{2}}}=\lambda_{k}^{m_{1}}-\lambda_{k}^{m_{2}}, k=1, \ldots, K .
$$

The covariation of exchange rates with financial assets abroad have to satisfy the condition that they convert foreign prices of risk into local prices of risk. Intuitively put, the above result 
makes explicit the crucial role of exchange rate variability in financially integrated markets. This leads to the main insight of this paper: that in financially integrated markets, investment returns (measured in domestic currency) should be priced by the same (domestic) prices of risk, independent of whether it is a domestic or foreign investment. Moreover, exchange rate operations involved in investing abroad prevent domestic agents to profit from (higher) prices of risk in the foreign market since these exchange rate operations will convert foreign prices of risk to domestic ones.

The above framework allows us to assess the effects of monetary unification. Monetary unification restricts exchange rate variability to zero, which in its turn, by virtue of the noarbitrage conditions, implies an immediate convergence of both the instantaneous riskless interest rates and the prices of risk:

$$
\begin{aligned}
r^{m_{1}}(t) d t & =r^{m_{2}}(t) d t \\
\lambda_{k}^{m_{1}} & =\lambda_{k}^{m_{2}}, k=1, \ldots, K
\end{aligned}
$$

As such, we have a natural way of testing the likely size of the financial market pricing effects from a monetary unification in the form of the difference between the market prices of risk across countries. To the extent that the market prices of risk differ across countries being part of a monetary union, these prices must converge to new, identical prices of risk valid in each and every country. If on the contrary, there is no significant difference in the prices of risk before monetary unification, little effects will be observed on excess returns in case of a monetary unification. To measure the potential effects of monetary unification it is therefore crucial to measure and test for the difference in prices of risk across countries.

As noted earlier, the assumption of a factor generating process for the exchange rate that is equal to the factor generating process of asset returns, is crucial for the above analysis to hold. However, when not all exchange rate shocks, orthogonal to asset markets can be diversified away, additional risk factors exist and the APT model cannot be readily extended to an IAPT model. However, Ikeda (1991) shows that under this more relaxing assumption APT can still be extended to an international setting for hedged returns.

\subsection{Testing for integration}

In order to make the test for integration operational we recast the above ideas into a discrete time multi-country framework. Define the $(N M \times 1)$ vector $r_{t}^{m_{1}}$ containing returns denominated in currency $m_{1}$ at some moment in time $t$ :

$$
r_{t}^{m_{1}}=\left(\begin{array}{l}
r_{m_{1}, t}^{m_{1}} \\
\vdots \\
r_{M, t}^{m_{1}}
\end{array}\right)
$$

where $r_{m_{2}, t}^{m_{1}}$ is the $(N \times 1)$ vector containing returns of country $m_{2}$ denominated in currency $m_{1}$. Note that a superscript index $m_{1}$ refers to the common currency denomination, whereas the subscript index $m_{2}$ refers to the local currency denomination. 
Assume the following factor structure for currency $m_{1}$ denominated returns:

$$
\left(r_{t}^{m_{1}}-\mu^{m_{1}}\right)=L^{m_{1} \prime} F_{t}+\varepsilon_{t}^{m_{1}}
$$

where $\mu^{m_{1}}$ is the mean return, $L^{m_{1}}$ is a $(K \times N M)$ matrix of factor sensitivities, $F_{t}$ is a $(K \times 1)$ vector of common risk factors, and $\varepsilon_{t}^{m_{1}}$ is an $(N M \times 1)$ vector of idiosyncratic components. Note that the same factor structure holds for the $(N M \times 1)$ vector $r_{t}^{m_{2}}$ containing returns denominated in currency $m_{2}$ at some moment in time $t$. This way we impose that the return vector, independent of the currency of denomination, depends on the same factors $F_{t}$ :

$$
\left(r_{t}^{m_{2}}-\mu^{m_{2}}\right)=L^{m_{2} \prime} F_{t}+\varepsilon_{t}^{m_{2}}
$$

Absence of arbitrage implies in a large economy that:

$$
\mu^{m_{1}} \approx \iota \lambda_{0}^{m_{1}}+\left(\begin{array}{lllll}
L_{m_{1}}^{m_{1} \prime} & 0 & \cdots & \cdots & 0 \\
0 & L_{m_{2}}^{m_{1} \prime} & 0 & \cdots & \vdots \\
\vdots & & & & 0 \\
0 & \cdots & \cdots & 0 & L_{M}^{m_{1} \prime}
\end{array}\right) \cdot\left(\begin{array}{l}
\lambda_{m_{1}, K}^{m_{1}} \\
\lambda_{m_{2}, K}^{m_{1}} \\
\vdots \\
\vdots \\
\lambda_{M, K}^{m_{1}}
\end{array}\right)
$$

where $\lambda_{0}^{m_{1}}$ is the zero-beta parameter, which is equal to the risk-free return (when such a risk-free asset exists), $L_{m_{2}}^{m_{1}}$ is the $(K \times N)$ matrix of factor loadings of the country $m_{2}$ assets, denominated in currency $m_{1}$ and $\lambda_{m_{2}, K}^{m_{1}}$ is the $(K \times 1)$ vector of factor risk premia or market prices of risk for currency $m_{1}$ denominated returns of country $m_{2}$. From the discussion in the previous section, we can define integration as a situation where prices of risk would be equalized dependent of the nationality of (currency denomination used by) the investor. More formally this amounts to imposing:

$$
\lambda_{m_{1}, K}^{m_{1}}=\lambda_{m_{2}, K}^{m_{1}}=\ldots=\lambda_{M, K}^{m_{1}}=\lambda_{K}^{m_{1}}
$$

such that the model reduces to:

$$
\mu^{m_{1}}-r_{f}^{m_{1}} \approx L^{m_{1} \prime} \lambda_{K}^{m_{1}}
$$

where the prices of risk are still dependent of the currency denomination index $m_{1}$, but are the same for an international portfolio with assets denominated in a single common currency. This model basically tests whether financial markets are integrated from the viewpoint of a certain investor.

The stronger test for integration amounts to testing for independence of market prices of risk with respect to the viewpoint. If market prices of risk are the same irrespective of the currency of denomination, the covariance between the asset market and the exchange market are zero. Formally this is tested as:

$$
\left(\begin{array}{l}
\mu^{m_{1}} \\
\vdots \\
\mu^{M}
\end{array}\right)-\left(\begin{array}{l}
r_{f}^{m_{1}} \\
\vdots \\
r_{f}^{M}
\end{array}\right) \approx\left(\begin{array}{lll}
L^{m_{1} \prime} & \ldots & 0 \\
0 & \ddots & 0 \\
0 & \ldots & L^{M^{\prime}}
\end{array}\right) \cdot\left(\begin{array}{l}
\lambda_{K}^{m_{1}} \\
\vdots \\
\lambda_{K}^{M}
\end{array}\right)
$$


where we impose:

$$
\lambda_{K}^{m_{1}}=\ldots=\lambda_{K}^{M}=\lambda_{K}
$$

\section{Empirical Results}

\subsection{Methodology}

In a first step factor analysis is used to extract the latent risk factors and the corresponding loadings on these factors ${ }^{5}$. Denote the $N M$-dimensional vector of de-meaned currency $m$ denominated returns by $\widetilde{r}_{t}^{m}$ for $t=1, \ldots, T$. When applying factor analysis to these returns jointly for more viewpoints, the underlying idea is that the returns can be expressed as a linear function of $K\left(K<\left(N M^{2}\right)\right)$ latent (risk-) factors:

$$
\left(\begin{array}{l}
\widetilde{r}_{t}^{1} \\
\vdots \\
\widetilde{r}_{t}^{M}
\end{array}\right)=\widetilde{r}_{t}=L^{\prime} F_{t}+\varepsilon_{t}
$$

with:

$$
\begin{array}{rll}
E\left(r_{t}\right)=\mu & E\left(r_{t} r_{t}^{\prime}\right)=\Sigma \\
E\left(F_{t}\right)=0 & E\left(F_{t} F_{t}^{\prime}\right)=I_{m} \\
E\left(\varepsilon_{t}\right)=0 & E\left(\varepsilon_{t} \varepsilon_{t}^{\prime}\right)=\Psi(\text { diagonal })
\end{array}
$$

To estimate this factor model, we cannot use standard estimation techniques as neither $L$ nor $F_{t}$ is known. Inspection of the above model, however implies the following covariance structure:

$$
\Sigma=L L^{\prime}+\Psi
$$

which is independent of the factors $F_{t}$, such that the elements of $L$ can now be determined. The estimation method is factoring by principal components. Practically, this is done by computing the first $K$ principal components of the estimated covariance matrix $\widehat{\Sigma}$ which defines the unknown factors and factor loadings ss $^{6}$ :

$$
\begin{aligned}
& L=\left[\begin{array}{lll}
\sqrt{\Lambda_{1,1}} e_{1} \cdot \sqrt{\frac{\Lambda_{1,1}-\sigma^{2}}{\Lambda_{1,1}}} & \cdots & \sqrt{\Lambda_{K, K}} e_{K} \cdot \sqrt{\frac{\Lambda_{K, K}-\sigma^{2}}{\Lambda_{K, K}}}
\end{array}\right] \\
& F_{t}=\left[\begin{array}{c}
\frac{1}{\sqrt{\Lambda_{1,1}}} e_{1}^{\prime} \widetilde{r}_{t} \\
\vdots \\
\frac{1}{\sqrt{\Lambda_{K, K}}} e_{K}^{\prime} \widetilde{r}_{t}
\end{array}\right]
\end{aligned}
$$

\footnotetext{
${ }^{5}$ Johnson, R.A. and D.W. Wichern (1982).

${ }^{6}$ See appendix A for a derivation of these results.
} 
where $\Lambda_{1,1}>\ldots>\Lambda_{K, K}$ are the $K$ largest eigenvalues of $\widehat{\Sigma}, e_{1}, \ldots, e_{K}$ are the normalized corresponding eigenvectors ${ }^{7}$ and $\sigma^{2}$ is the residual variance (i.e. the remaining eigenvalues):

$$
\sigma^{2}=\frac{\sum_{k=k+1}^{N M} \Lambda_{k, k}}{((N M \times M)-K)}
$$

This factor is a scale factor by which the ordinary principal components have to multiplied due to upward bias. Note also that the above solution is not unique. If $T$ is any orthogonal matrix, then $L^{*}=T L$ and $F^{*}=T^{\prime} F$, is also a solution to the above problem. This rotational indeterminacy allows one to impose economic structure on the factors, while leaving the variance unchanged. If one imposes $T=I$, the factor solution is uniquely determined, except for a sign change.

From the above derivation, it can be seen that factor analysis does not impose a priori the number of risk sources and their structure or economic interpretation. Factor analysis is a statistical description of the data, where one tries to summarize the variation in the data as compactly as possible. This methodology is exactly the opposite of the methodology of formal interest rate models, where the number of sources and their economic structure is imposed in advance. To determine the appropriate number of factors, there exist numerous heuristic devices. The following device is often used. For each factor $k$ we can calculate the proportion of the total sample variance explained due to that factor:

$$
\frac{\Lambda_{k, k}}{\operatorname{tr}(\widehat{\Sigma})}
$$

The cumulative sample variance explained, is obtained by summing this measure over the consecutive factors. When the cumulative sample variance explained is rather high, and additional factors only explain a negligible part of the variance, the factor model is supposed to fit the data well. One can additionally calculate the uncentered $\mathrm{R}^{2}$ per country per return series $n^{8}$ :

$$
\frac{\sum_{t=1}^{T}\left(L_{n}^{\prime} F_{t}\right)^{\prime}\left(L_{n}^{\prime} F_{t}\right)}{\sum_{t=1}^{T} \widetilde{r}_{n, t}^{\prime} \widetilde{r}_{n, t}}
$$

This measure will give an idea of the fit of the factor model per country per return series.

In a second step, we estimate the cross-section market prices of risk vector $\lambda_{K}^{m}$ separately for each viewpoint $m=1, \ldots, M \operatorname{as}^{9}$ :

$$
\mu^{m}-r_{f}^{m}=L^{m} \lambda_{M}^{m}+\eta^{m}
$$

\footnotetext{
${ }^{7}$ Every multiple of an eigenvector is also a valid eigenvector. Therefore we normalized the eigenvectors such that $e_{k} e_{k}^{\prime}=1$.

${ }^{8}$ We use the uncentered $\mathrm{R}^{2}$ as we use demeaned data.

${ }^{9}$ See Cochrane (2001).
} 
We use the first step generalized method of moments of Hansen (1982) using the factor loadings obtained from the factor analysis ${ }^{10}$. Since the $(N M \times 1)$ vector of excess returns $\left(\mu^{m}-r_{f}^{m}\right)$ is explained in terms of $K$ market prices of risk, we are left with $(N M-K)$ testable restrictions. The overidentifying restrictions test is calculated as:

$$
\xi^{m}=\widehat{\eta}^{m \prime} \cdot\left[\operatorname{cov}\left\{\widehat{\eta}^{m}\right\}\right]^{+} \cdot \widehat{\eta}^{m}
$$

where $\widehat{\eta}^{m}$ are the estimated moment conditions and where + indicates a pseudo-inverse as this matrix is generally not invertible. This test statistic is $\chi^{2}$ distributed with $(N M-K)$ degrees of freedom. A small GMM J-statistic (with a p-value larger than 0.05) implies that the overall fit of the model is good (pricing errors are zero) and thus that risk is equally priced across the countries contained in a portfolio. This can be interpreted as markets being financially integrated.

To test the stronger notion of integration -market prices of risk are independent of the numeraire chosen- we re-estimate the market prices of risk, jointly for the $M$ viewpoints and test for the equality of the risk prices. This results in a $\chi^{2}$-statistic with $\left(N M^{2}-K\right)$ degrees of freedom. If this restricted model fits the data well, exchange rates do not correlate strongly with asset markets, and exchange rate variability is thus not priced.

\subsection{Data Description}

The empirical analysis covers data on 8 countries, namely the US (USD), the UK (GBP), Japan (JPY), Germany (DEM), Belgium (BEF), the Netherlands (NLG), France (FRF) and Austria (ATS) ${ }^{11}$ Returns are calculated as monthly returns. For each country we calculated 2 returns $(N=2)$. The first return is the return on a bond portfolio, with equal weighting of the 2 year, 3 year, 5 year, 7 year and 10 year government bonds (benchmark government index). The second return is the MSCI total return index (net dividends included). Excess returns are calculated using the 1 month LIBOR return as the risk-free rate. Common returns are computed with end-of-month exchange rates. The period covered is January 1990 until December 2000. All data are collected from Datastream.

To get a better understanding of the degree of financial integration in EMU markets the analysis is performed on different bilateral investment portfolios (integration among $M=2$ countries). Germany and the US are the benchmark countries (principal currency denominations), in that they are always combined with one of the other countries. Each analysis is always performed in both currency denominations. In table 1 we present summary statistics on the common DEM currency returns. In table 2 we also present common USD currency returns. As expected mean returns on the bond portfolio are lower compared to mean returns on the MSCI index, except for Austria in common DEM currency, and for Germany,

\footnotetext{
${ }^{10}$ As a rule of thumb it is stated that one should take up no more moments than one tenth of the time-series length of the dataset (see for instance chapter five in Campell, Lo and MacKinlay (1997)). In our case, we should take up no more than thirteen moments, which is a rule to which we abide.

${ }^{11} \mathrm{As}$ in the theoretical part, a subscript refers to the local currency denomination and a superscript, to the common currency denomination in which the returns are converted.
} 
Japan, Belgium and Austria in common USD currency. Standard deviations are very large compared to mean returns, and this is especially true for the MSCI returns. Moreover, standard deviations for common DEM currency returns are smaller compared to common USD currency returns. Finally the kurtosis, skewness and normality statistics for several returns series indicate that they are significant.

Table 1: Descriptive Statistics Common DEM Currency Returns

\begin{tabular}{|c|c|c|c|c|c|}
\hline & MEAN & $\begin{array}{l}\text { STANDARD } \\
\text { DEVIATION }\end{array}$ & KURTOSIS & "SKEWNESS & "NORMALITY \\
\hline$r b_{u s d}^{\text {dem }}$ & 0.091 & 0.098 & 2.436 & 0.130 & 2.104 \\
\hline$r b_{g b p}^{d e m}$ & 0.121 & 0.103 & $5.432^{*}$ & 0.308 & $34.365^{*}$ \\
\hline$r b_{d e m}^{d e m}$ & 0.083 & 0.045 & $4.385^{*}$ & $-0.564^{*}$ & $17.420^{*}$ \\
\hline$r b_{j p y}^{d e m}$ & 0.104 & 0.117 & $4.738^{*}$ & $0.583^{*}$ & $23.906^{*}$ \\
\hline$r b_{\text {bef }}^{\text {dem }}$ & 0.103 & 0.054 & $4.292^{*}$ & $0.506^{*}$ & $14.709^{*}$ \\
\hline$r b_{n \lg }^{\text {dem }}$ & 0.086 & 0.045 & 3.808 & -0.137 & 3.978 \\
\hline$r b_{f r f}^{\text {dem }}$ & 0.099 & 0.054 & 3.311 & 0.151 & 1.025 \\
\hline$r b_{a t s}^{\text {dem }}$ & 0.086 & 0.039 & 3.823 & -0.285 & 5.471 \\
\hline$r s_{u s d}^{d e m}$ & 0.183 & 0.174 & 3.240 & 0.223 & 1.401 \\
\hline$r s_{g b p}^{d e m}$ & 0.148 & 0.169 & 3.042 & 0.053 & 0.071 \\
\hline$r s_{d e m}^{d e m}$ & 0.128 & 0.201 & $4.238^{*}$ & $-0.485^{*}$ & $13.498^{*}$ \\
\hline$r s_{j p y}^{d e m}$ & 0.041 & 0.271 & $4.459^{*}$ & 0.323 & $13.888^{*}$ \\
\hline$r s_{\text {bef }}^{\text {dem }}$ & 0.124 & 0.162 & $4.120^{*}$ & $-0.465^{*}$ & $11.578^{*}$ \\
\hline$r s_{n \lg }^{d e m}$ & 0.175 & 0.160 & 3.554 & $-0.431^{*}$ & 5.732 \\
\hline$r s_{f r f}^{d e m}$ & 0.150 & 0.189 & 2.873 & -0.257 & 1.535 \\
\hline$r s_{\text {ats }}^{\text {dem }}$ & 0.011 & 0.230 & $4.564^{*}$ & -0.380 & $16.518^{*}$ \\
\hline
\end{tabular}

Notes: $r b$ denotes the return on the bond-index portfolio, and $r s$ denotes the return on the MSCI-index, both on an annual basis (following equation (6)). * indicates significance at the $5 \%$ level.

Table 3 presents cross-country common DEM currency correlations averaged over the complete set of returns. Table 4 presents the same correlations, but based on common USD currency returns. Not surprisingly, correlations are largest between the different EMU member states. This however only implies that EMU financial markets are most linked with each other and thus pure country diversification strategies are less profitable at the EMU level. It does not yet imply that the EMU markets are financially integrated.

\subsection{Empirical Results IAPT}

Whether the stronger linkage is translated into a higher degree of financial integration is exactly what will be examined by modelling an IAPT. As described in the theoretical part, we first perform a factor analysis, jointly for two viewpoints and fit an IAPT for returns, first, for the viewpoint of each country separately, and next for the joint viewpoints. The first methodology allows us to test whether IAPT fits the data well. The second methodology 
Table 2: Descriptive Statistics Common USD Currency Returns

\begin{tabular}{l|ccccc}
\hline \hline & MEAN & $\begin{array}{c}\text { STANDARD } \\
\text { DEVIATION }\end{array}$ & KURTOSIS & SKEWNESS & NORMALITY \\
\hline \hline$r b_{\text {usd }}^{\text {usd }}$ & 0.084 & 0.054 & 3.367 & 0.039 & 0.769 \\
$r b_{\text {gbp }}^{\text {usd }}$ & 0.089 & 0.120 & $5.517^{*}$ & -0.075 & $34.693^{*}$ \\
$r b_{\text {dem }}^{\text {usd }}$ & 0.053 & 0.107 & 3.572 & 0.398 & 5.249 \\
$r b_{j p d}^{\text {usd }}$ & 0.085 & 0.124 & $8.300^{*}$ & $1.495^{*}$ & $202.101^{*}$ \\
$r b_{b e f}^{\text {usd }}$ & 0.068 & 0.107 & 3.437 & 0.404 & 4.597 \\
$r b_{n \text { lg }}^{\text {usd }}$ & 0.055 & 0.105 & 3.496 & 0.373 & 4.379 \\
$r b_{f r f}^{\text {usd }}$ & 0.064 & 0.105 & 3.358 & 0.402 & 4.223 \\
$r b_{\text {ats }}^{\text {usd }}$ & 0.054 & 0.102 & 3.552 & 0.316 & 3.847 \\
\hline$r s_{\text {usd }}^{\text {usd }}$ & 0.157 & 0.138 & $3.933^{*}$ & $-0.442^{*}$ & $9.011^{*}$ \\
$r s_{g b p}^{\text {usd }}$ & 0.095 & 0.174 & 3.630 & 0.252 & 3.557 \\
$r s_{\text {dem }}^{\text {usd }}$ & 0.048 & 0.304 & $4.245^{*}$ & $-0.469^{*}$ & $13.266^{*}$ \\
$r s_{\text {jpd }}^{\text {usd }}$ & 0.004 & 0.273 & $6.911^{*}$ & $0.898^{*}$ & $101.085^{*}$ \\
$r s_{\text {bef }}^{\text {usd }}$ & 0.062 & 0.181 & $4.239^{*}$ & 0.193 & $9.193^{*}$ \\
$r s_{n \text { usd }}^{\text {lod }}$ & 0.091 & 0.167 & 3.588 & -0.002 & 1.887 \\
$r s_{\text {frd }}^{\text {usd }}$ & 0.080 & 0.208 & 3.549 & 0.269 & 3.221 \\
$r s_{\text {ats }}^{\text {usd }}$ & -0.071 & 0.251 & $5.774^{*}$ & 0.074 & $42.134^{*}$ \\
\hline \hline
\end{tabular}

Notes: $r b$ denotes the return on the bond-index portfolio, and $r s$ denotes the return on the MSCI-index, both on an annual basis (following equation (6)). * indicates significance at the $5 \%$ level.

Table 3: Common DEM Currency Return Correlations

\begin{tabular}{c|llllllll}
\hline \hline & $r_{u s d}^{\text {dem }}$ & $r_{\text {gbp }}^{\text {dem }}$ & $r_{\text {dem }}^{\text {dem }}$ & $r_{j p y}^{\text {dem }}$ & $r_{\text {bef }}^{\text {dem }}$ & $r_{n \mathrm{lg}}^{\text {dem }}$ & $r_{\text {frf }}^{\text {dem }}$ & $r_{\text {ats }}^{\text {dem }}$ \\
\hline \hline$r_{\text {usd }}^{\text {dem }}$ & 1 & & & & & & & \\
$r_{\text {gbp }}^{\text {dem }}$ & 0.58 & 1 & & & & & & \\
$r_{\text {dem }}^{\text {dem }}$ & 0.47 & 0.47 & 1 & & & & & \\
$r_{j p y}^{\text {dem }}$ & 0.42 & 0.32 & 0.36 & 1 & & & & \\
$r_{\text {bef }}^{\text {dem }}$ & 0.44 & 0.49 & 0.70 & 0.29 & 1 & & & \\
$r_{n \text { dg }}^{\text {dem }}$ & 0.53 & 0.54 & 0.86 & 0.37 & 0.76 & 1 & & \\
$r_{\text {dem }}^{\text {frf }}$ & 0.49 & 0.51 & 0.78 & 0.33 & 0.76 & 0.80 & 1 & \\
$r_{\text {ats }}^{\text {dem }}$ & 0.40 & 0.45 & 0.78 & 0.31 & 0.61 & 0.76 & 0.65 & 1 \\
\hline \hline
\end{tabular}

Notes: Entries are cross-country common DEM currency return correlations, averaged over the 2 returns. 


\section{Table 4: Common USD Currency Return Correlations}

\begin{tabular}{|c|c|c|c|c|c|c|c|c|}
\hline & $\begin{array}{l}r_{u s d}^{u s d} \\
\end{array}$ & $\begin{array}{l}r_{g b p}^{u s d} \\
b\end{array}$ & $r_{\text {dem }}^{\text {usd }}$ & $\overline{r_{j p y}^{u s d}}$ & $\begin{array}{l}r_{b e f}^{u s d} \\
\end{array}$ & $\begin{array}{l}r_{n \mathrm{lg}}^{u s d} \\
\text { us }\end{array}$ & $\overline{r_{\text {r }}^{u s d}}$ & $r_{\text {ats }}^{\text {usd }}$ \\
\hline$r_{u s d}^{u s d}$ & 1 & & & & & & & \\
\hline$r_{g b p}^{u s d}$ & 0.52 & 1 & & & & & & \\
\hline$r_{d e m}^{u s d}$ & 0.52 & 0.62 & 1 & & & & & \\
\hline$r_{j p y}^{u s d}$ & 0.37 & 0.36 & 0.47 & 1 & & & & \\
\hline$r_{b e f}^{u s d}$ & 0.48 & 0.62 & 0.81 & 0.42 & 1 & & & \\
\hline$r_{n \mathrm{lg}}^{u s d}$ & 0.55 & 0.68 & 0.88 & 0.47 & 0.87 & 1 & & \\
\hline$r_{f r f}^{u s d}$ & 0.50 & 0.65 & 0.85 & 0.45 & 0.85 & 0.88 & 1 & \\
\hline$r_{\text {ats }}^{\text {usd }}$ & 0.40 & 0.56 & 0.84 & 0.42 & 0.73 & 0.80 & 0.75 & 1 \\
\hline
\end{tabular}

Notes: Entries are cross-country common USD currency return correlations, averaged over the 2 returns.

allows us to test what the impact is of the exchange rate variability via the covariance between exchange rates and the asset market.

In a first part, factor analysis is used to extract the latent factors and the corresponding factor sensitivities. Each time we extract three factors $(K=3)$, as this number of factors always explains the major part of the variance of the data. Table 5 shows the cumulative variance explained by the three factors for the thirteen portfolios of assets. From this it is clear that three factors seem to capture the major part of the variance in the data, ranging from $88.51 \%$ of the total variance explained up to a high $99.82 \%$. It can be noted that the highest variance is explained for EMU combinations of assets. This is again an indication that EMU markets are most correlated with each other.

Table 5: Cumulative Variance Explained by a 3 Factor Model (in \%)

\begin{tabular}{cc|cc}
\hline \hline PORTFOLIO & CUM. VAR & PORTFOLIO & CUM.VAR \\
\hline \hline DEM-USD & 93.01 & USD-GBP & 88.51 \\
DEM-GBP & 91.72 & USD-JPY & 93.97 \\
DEM-JPY & 94.96 & USD-BEF & 92.30 \\
DEM-BEF & 98.66 & USD-NLG & 92.04 \\
DEM-NLG & 99.88 & USD-FRF & 92.60 \\
DEM-FRF & 98.70 & USD-ATS & 94.79 \\
DEM-ATS & 99.82 & & \\
\hline \hline
\end{tabular}

Appendix $\mathrm{B}$, table 8 contains the uncentered $R^{2}$ which gives an idea of the explanatory power of the three factor model for each of the separate time-series of returns. Inspection of these results indicate that the $R^{2}$ is generally higher for EMU portfolios than for nonEMU portfolios. Note also the high dispersion between the $R^{2}$ of some bond indices and MSCI indices in the case of non-EMU combinations. When considering only two factors, this phenomenon is even more pronounced. This is one more reason to focus on three factors. 
In a second step, we estimate the cross-section IAPT-relation for each portfolio (for each viewpoint included in the portfolio). This yields estimates of the market prices of risk and of the GMM-overidentifying restrictions test. The results are presented in tables 6 and 7 for the DEM and the USD benchmark portfolio respectively.

Table 6 shows that the IAPT model for the point of view of a single currency denomination is in almost all cases accepted. That is, German investors, investing abroad do earn expected excess returns based on the German prices of risk. Changing the currency viewpoint, does not alter these conclusions in general, e.g. a Belgian investor, investing in Germany earns excess returns based on Belgian prices of risk. Only in the case of the DEM-USD and the DEM-JPY portfolio, the model is rejected for the foreign viewpoint. These results lead us to conclude that the German market is integrated with the other markets considered here, as returns to risk taking are determined by the local prices of risk. The column "joint" tests for the cross-sectional restrictions when imposing the equality of prices of risk across countries. Typically, this hypothesis is rejected for all the portfolios combining German assets with nonEMU assets. On the other hand, the model with portfolios combining German assets with EMU assets is not rejected. This implies that across the European countries, exchange rate variability did not allow these countries to have highly different pricing behavior. In fact we cannot reject the hypothesis implying that the pricing behavior as far as prices of risk is concerned was identical across countries. This in its turn implies that the exchange rate movements during the ERM period were largely unrelated to European bond and stock markets creating but a nuisance factor in international investments that could easily be hedged away. The consequences for the effects of monetary unification, i.e. the elimination of exchange rate movement, has therefore not affected the functioning, i.e. pricing of excess returns, in any significant way ${ }^{12}$. For the non-EMU combinations this is obviously not the case. There we reject the equality of prices of risk across countries, suggesting a crucial role for the exchange rate in terms of conversion of prices of risk across countries. This conversion property shows up in the significant covariation of exchange rates and financial asset returns across this type of countries.

A graphical representation of these results can be found in figure 1. These figures give a pricing error representation of the IAPT model for all of the DEM benchmark portfolios for the viewpoint of a German investor. A graphical representation of the other viewpoints can be found in appendix $\mathrm{C}$, in figure 3 for the foreign viewpoints and figure 4 for the joint viewpoints. Mean excess returns are plotted on the horizontal axis, while mean excess returns, estimated by the IAPT model are plotted on the vertical axis. The closer the estimates to the $45^{\circ}$-line, the better the fit of the model. The figures clearly indicate that the model fit is better for EMU portfolios, than for non-EMU combinations. In the non-EMU portfolios, we see one outlier when estimated for a single viewpoint. In all cases the outlier is the home currency bond index return.

These findings can even be reinforced when looking at a graphical representation of the

\footnotetext{
${ }^{12}$ The model was also estimated for the ERM period (January 1990 until December 1998), to eliminate the effects of monetary unification. This did not alter the results. We therefore only report the full sample results.
} 

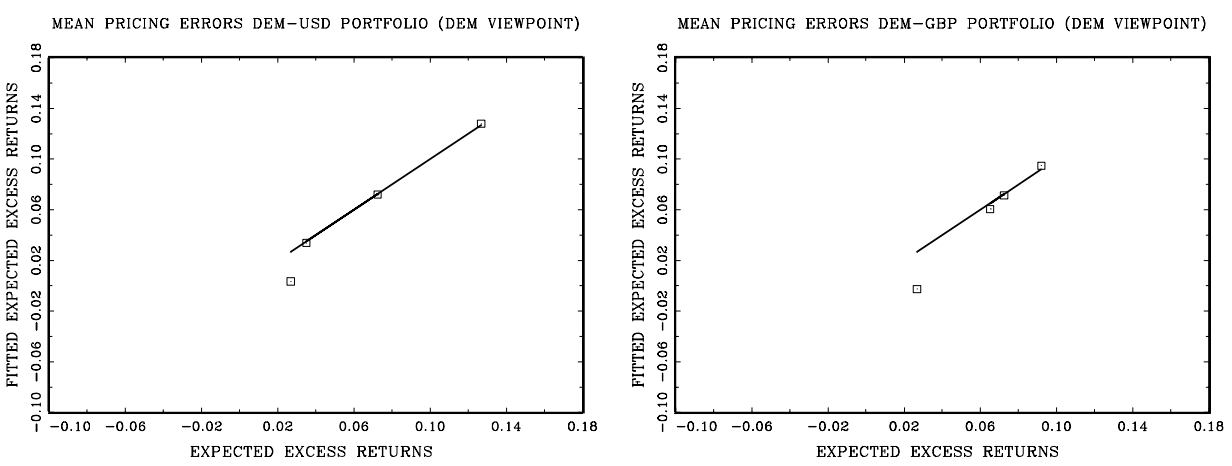

MEAN PRICING ERRORS DEM-JPY PORTFOLIO (DEM VIEWPOINT)
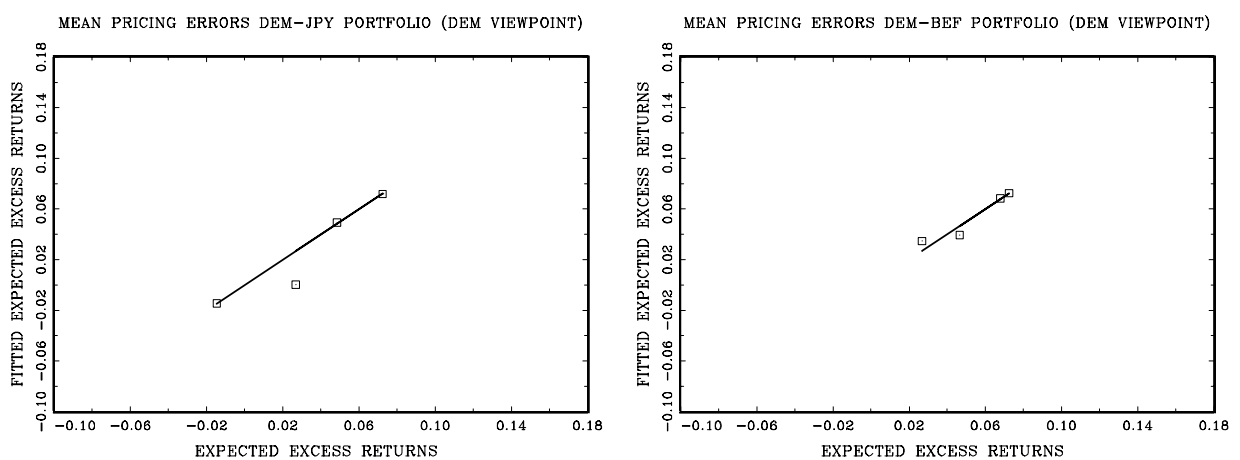

MEAN PRICING ERRORS DEM-NLG PORTFOLIO (DEM VIEWPOINT)

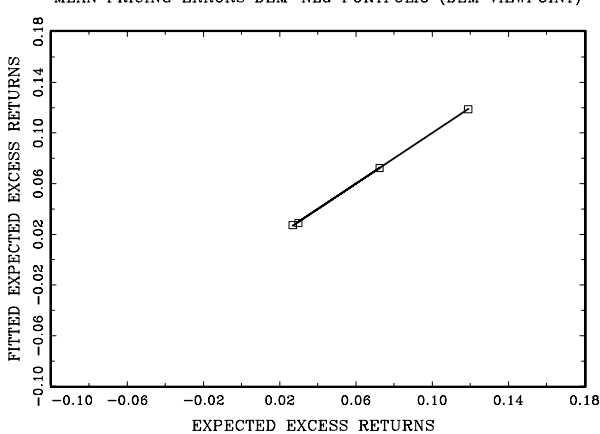

MEAN PBICINC FRBOBS DFM-FBF POBTFOHO (DEM VIEWPONT)

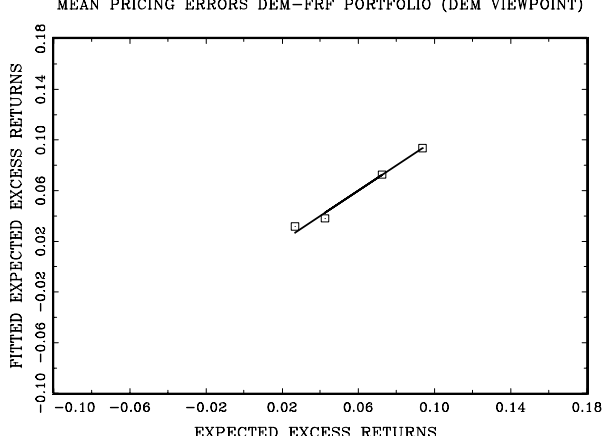

MEAN PRICING FRRORS DEM-ATS PORTFOITO (DEM VIEWPOINT)

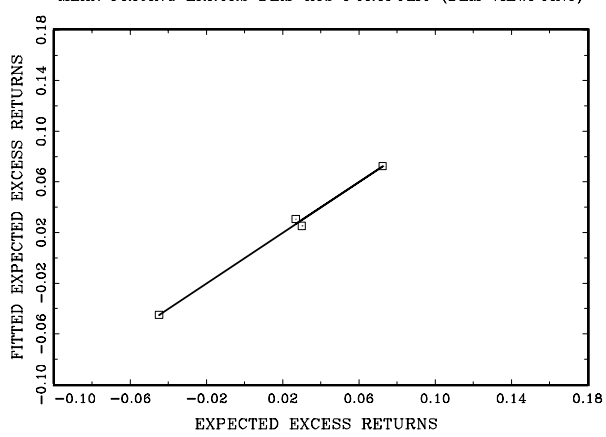

Figure 1: Pricing Errors DEM Benchmark Portfolio (DEM Viewpoint) 
Table 6: $\chi^{2}$ (p-value) of DEM Benchmark Portfolios

\begin{tabular}{c|ccc}
\hline \hline & \multicolumn{3}{|c}{ VIEWPOINT } \\
\hline \hline PORTFOLIO & DEM (HOME) & FOREIGN & JOINT \\
\hline DEM-USD & $2.84(0.09)$ & $4.77(0.03)$ & $20.28(0.00)$ \\
DEM-GBP & $3.76(0.05)$ & $2.91(0.09)$ & $11.75(0.04)$ \\
DEM-JPY & $3.97(0.05)$ & $6.08(0.01)$ & $19.59(0.00)$ \\
DEM-BEF & $1.98(0.16)$ & $1.49(0.22)$ & $9.16(0.10)$ \\
DEM-NLG & $0.16(0.69)$ & $0.17(0.68)$ & $10.40(0.06)$ \\
DEM-FRF & $0.87(0.35)$ & $0.92(0.34)$ & $3.12(0.68)$ \\
DEM-ATS & $2.43(0.12)$ & $2.52(0.11)$ & $10.56(0.06)$ \\
\hline \hline
\end{tabular}

Notes: Entries are the GMM overidentifying restrictions statistic (equation (20)) and the corresponding p-value. The entries under the heading DEM and FOREIGN relate to the testing of equation (17), whereas the entries under the heading JOINT relate to the testing of equation (18). A p-value larger than 0.05 indicates that model fit is good at the $5 \%$ significance level.

stochastic discount factors across the different viewpoints. Given the estimated factors and the estimated market prices of risk, the stochastic discount factor, based on currency $m$ denomination $m_{t}^{m}$ can be constructed as:

$$
m_{t}^{m}=-\lambda^{m \prime} F_{t} \quad \text { for } t=1, \ldots, T
$$

By constructing these stochastic discount factors, we can reconstruct the actual implied excess returns across countries for every period in time. Instead of only looking at average excess returns we now reconstruct the implied excess returns over time. These time series give us additional information related to the precision of the pricing relation. When market prices of risk are independent of the viewpoint chosen, the stochastic discount factors should be equal when constructed on market prices of risk of the DEM, foreign and joint viewpoints. Appendix E shows these stochastic discount factors for the DEM benchmark portfolios. From these, it can be seen that for the EMU portfolios we indeed find viewpoint independent stochastic discount factors (i.e. stochastic discount factors clearly are situated on or close to the $45^{\circ}$ line), whereas this is not the case for the non-EMU portfolios. This is exactly what we could expect on the basis of the GMM overidentifying restrictions test.

Table 7 contains the IAPT estimation results for the USD benchmark portfolios. The GMM-overidentifying restrictions test is in almost all cases significant at the $5 \%$ level. This implies that IAPT does not fit the data well, which we interpret as markets not being integrated, as risk is not priced in the same way. Only for the USD-GBP, USD-JPY and USD-FRF portfolio, we see that the pricing errors are indeed statistically zero, whereas this is not the case when the analysis is performed jointly for both viewpoints.

For the USD portfolios we also constructed pricing error graphs. These can be found in figure 2 for the USD viewpoint, whereas the other viewpoints can be found in appendix D in figures 3 and 4 . These figures show that the pricing errors are large mainly due one outlier 
Table 7: $\chi^{2}$ (p-value) of USD Benchmark Portfolios

\begin{tabular}{c|ccc}
\hline \hline & \multicolumn{3}{|c}{ VIEWPOINT } \\
\hline \hline PORTFOLIO & USD (HOME) & FOREIGN & JOINT \\
\hline USD-GBP & $2.87(0.09)$ & $1.73(0.19)$ & $15.01(0.01)$ \\
USD-JPY & $3.14(0.08)$ & $3.87(0.05)$ & $17.20(0.00)$ \\
USD-BEF & $5.20(0.02)$ & $6.53(0.01)$ & $18.52(0.00)$ \\
USD-NLG & $4.79(0.03)$ & $4.23(0.04)$ & $24.21(0.00)$ \\
USD-FRF & $3.79(0.05)$ & $3.46(0.06)$ & $18.91(0.00)$ \\
USD-ATS & $5.93(0.01)$ & $5.50(0.02)$ & $18.64(0.00)$ \\
\hline \hline
\end{tabular}

Notes: Entries are the GMM overidentifying restrictions statistic (equation (20)) and the corresponding p-value. The entries under the heading USD and FOREIGN relate to the testing of equation (17), whereas the entries under the heading JOINT relate to the testing of equation (18). A p-value larger than 0.05 indicates that model fit is good at the $5 \%$ significance level.

for the individual viewpoints, whereas the joint estimates are overall less accurate. Finally, we also computed the stochastic discount factors for the different USD benchmark portfolios, based on the USD, foreign and joint viewpoints respectively. The graphical representation of this can be found in appendix F. These graphs make clear that market prices of risk are dependent of the viewpoint chosen. There is no conversion of market prices of risk as the covariance between the exchange market and the asset market plays an important role.

\section{Conclusion}

This paper examined the issue of financial integration in an IAPT framework where exchange risk is diversified. More specifically, we provided an empirical investigation of the degree of integration in (now) EMU and non-EMU portfolios for the period from 1990 through 2000. The analysis included two broad classes of investment for each country, namely a bond portfolio and the MSCI index. This allowed us to investigate the integration issue on a very broad level.

In a first step, we used factoring by principal components to extract three common latent risk factors. The set-up was such that all possible common currency denominations included in the portfolio, are dependent on the same common factors. In a second step, we estimated the cross-section market prices of risk separately for each currency denomination, and the joint currency denomination and we used the GMM overidentifying restrictions test to assess the overall fit of the model. A test statistic with a p-value larger than 0.05 implied that risk was equally priced across countries, which was interpreted as markets being financially integrated. Moreover the joint estimation investigated the market prices of risk conversion between currencies.

We found that the IAPT is a good description of the pricing of an EMU portfolios, while on the contrary the model had to be rejected for the non-EMU portfolios. This is thus evidence 

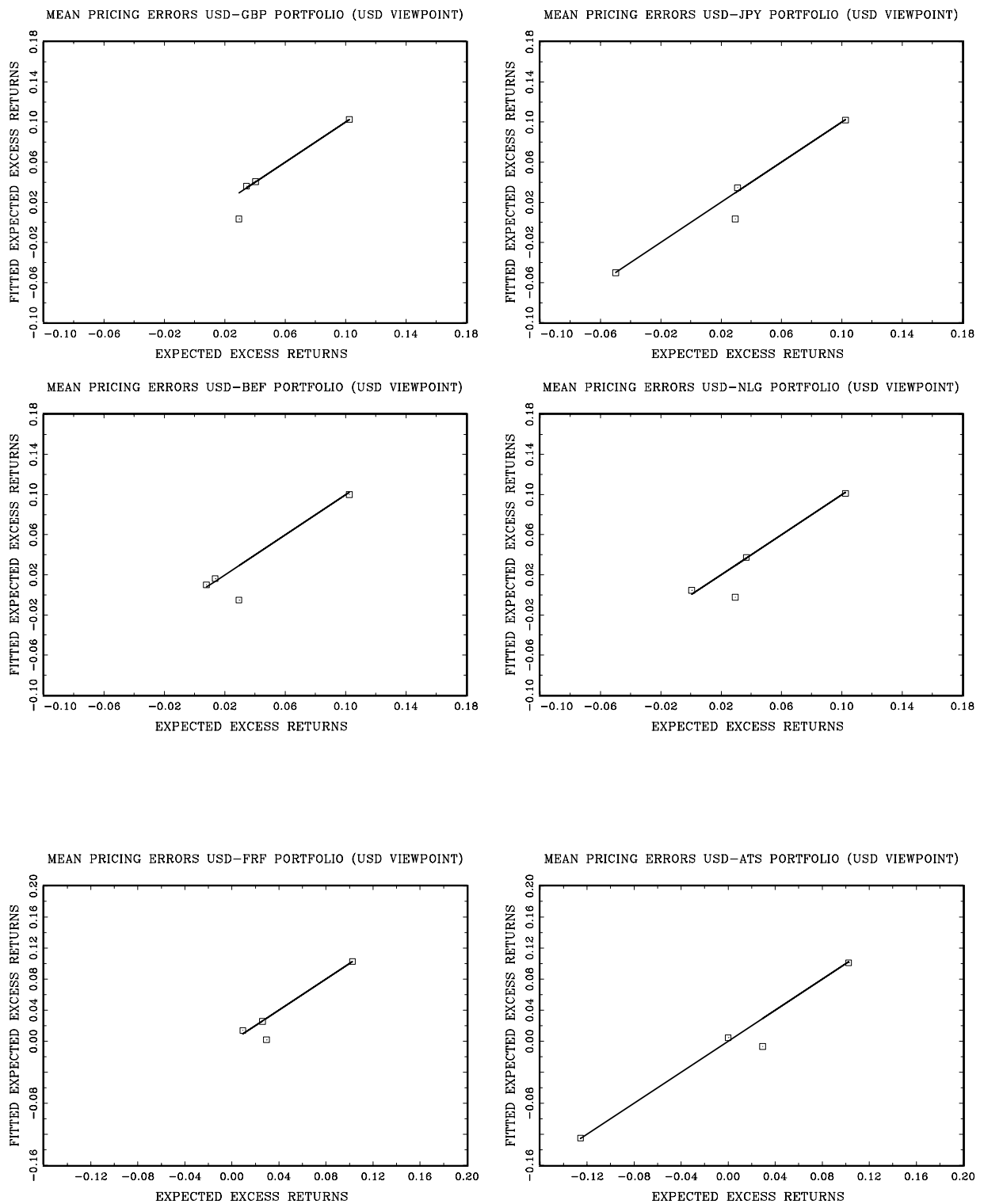

Figure 2: Pricing Errors USD Benchmark Portfolio (USD Viewpoint) 
in favor of an integrated EMU market. Moreover, the results for the EMU portfolio seem to be independent of the currency denomination used, as market prices of risk are almost completely alike across the different currency denominations. This suggests that the covariance between the asset market and the exchange market is negligible for the (now) EMU countries. For the non-EMU portfolios currency denomination does matter, which implies a non-zero covariance between asset markets and exchange markets.

The results allow us to assess with hindsight the effects of European monetary integration on the pricing of excess return across EMU countries. In fact since monetary unification eliminates all exchange rate variability, we focussed on the effect of exchange rate variability on the respective financial markets. Our conclusion is that (at least from an unconditional point of view) exchange rate variability did not really separate European financial markets, since the observed exchange rate changes are largely unrelated to changes in the European financial markets. In other words, we find that the exchange rate changes within Europe were mainly nuisance factors that could be hedged away without major implications for the excess returns. As such, it is obvious that the elimination of exchange rate movements did not exert great effects on observed excess returns during the EMU period.

Several caveats should be acknowledged. We mention two. First, it should be stressed that this study analyzed global financial markets in the sense that we only incorporated in the analysis the most liquid assets, i.e. various bond and the stock market indices. Our conclusions can obviously not be extended towards other indices or individual assets. Second, our analysis is unconditional in the sense that we only look at unconditionally expected excess returns. This procedure allowed us to abstain from having to choose a specific pricing model (and is thus quite generally valid). However, undoubtedly it also fails to incorporate very precise conditional events where no-arbitrage may have failed. To summarize these caveats in one sentence, our conclusions will hold "generally speaking", while clearly one could find specific events or assets where no-arbitrage may have failed very well also within European financial markets. 


\section{References}

[1] Adler, M. and B. Dumas (1983), International Portfolio Choice and Corporation Finance: A Synthesis, Journal of Finance, 38(3), pp.925-984.

[2] Basilevsky, A. (1994), Statistical Factor Analysis and Related Methods: Theory and Applications, John Wiley \& Sons, 737p.

[3] Bekaert, G. and R.J. Hodrick (1992), Characterizing Predictable Components in Excess Returns on Equity and Foreign Exchange Markets, Journal of Finance, 47(2), pp.467509.

[4] Bekaert, G. and C.R. Harvey (1995), Time-Varying World Market Integration, Journal of Finance, 50(2), pp.403-444.

[5] Bliss, R.R. (1997), Movements in the Term Structure of Interest Rates, Federal Reserve Bank of Atlanta Economic Review, 4th quarter, pp.16-33.

[6] Campbell, J.Y, A.W. Lo, and A.C. MacKinlay (1997), The Econometrics of Financial markets, Princeton University Press, 611p.

[7] Cho, D.C., C.S. Eun, and L.W. Senbet (1986), International Arbitrage Pricing Theory: An Empirical Investigation, Journal of Finance, 41(2), pp.313-329.

[8] Cochrane, J. (2001), Asset Pricing, Princeton University Press, 524p.

[9] Hansen, L. (1982), Large Sample Properties of Generalized Methods of Moments Estimators, Econometrica, 50, pp.1029-1054.

[10] Hardouvelis, G., D. Malliaropulos, and R. Priestley (1999), EMU and the European Stock Market Integration, CEPR Discussion Papers, no.2124, 66p.

[11] Huberman, G. and S. Kandel (1987), Mean Variance Spanning, Journal of Finance, 42(2), pp.873-888.

[12] Ikeda, S. (1991), Arbitrage Asset Pricing Under Exchange Risk, Journal of Finance, 46(1), pp.447-455.

[13] Johnson, R.A. and D.W. Wichern (1982), Applied Multivariate Statistical Analysis, Prentice-Hall, New York, 594p.

[14] Jorion, P. (1992), Term Premiums and the Integration of the Eurocurrency Markets, Journal of International Money and Finance, 11, pp.17-39.

[15] Jorion, P. and E. Schwartz (1986), Integration vs. Segmentation in the Canadian Stock Market, Journal of Finance, 41(3), pp.603-614. 
[16] Korajczyk, R.A. and C.J. Viallet (1989), An Empirical Investigation of International Asset Pricing, Review of Financial Studies, 2(4), pp.553-585.

[17] Licht, A.N. (1997), Stock Market Integration in Europe, Harvard Institute for International Development, CAERII Discussion Paper, no.15, 71p.

[18] Naranjo, A. and A. Protopapadakis (1997), Financial Market Integration Tests: an Investigation Using US Equity Markets, Journal of International Financial Markets, Institutions and Money, 7, pp.93-135.

[19] Ross, S.A. (1976), The Arbitrage Theory of Capital Asset Pricing, Journal of Economic Theory, 13, pp.341-360.

[20] Rose, A.K. and C. Engel (2000), Currency Unions and International Integration, NBER Working Paper, no.7872, 38p.

[21] Solnik, B. (1983), International Arbitrage Pricing Theory, Journal of Finance, vol.38, no.2, pp.449-457.

[22] Stulz, R.M. (1981), A Model of International Asset Pricing, Journal of Financial Economics, 9, pp.383-406.

[23] Stulz, R.M. (1994), International Portfolio Choice and Asset Pricing: An Integrative Survey, NBER Working Paper, no.4645, 44p. 


\section{A Factor Analysis}

An orthogonal factor model with $K$ common factors is summarized as follows:

$$
\underset{(N M \times 1)}{r_{t}-\mu}=\underset{(N M \times K)}{L_{(K \times 1)}^{\prime}} \underset{(N M \times 1)}{F_{t}}+\underset{(N)}{\varepsilon_{t}}
$$

with:

$$
\begin{array}{rlrl}
E\left(r_{t}\right) & =\mu & & E\left(r_{t} r_{t}^{\prime}\right)=\Sigma \\
E\left(F_{t}\right)=0 & & E\left(F_{t} F_{t}^{\prime}\right)=I_{m} \\
E\left(\varepsilon_{t}\right) & =0 & & E\left(\varepsilon_{t} \varepsilon_{t}^{\prime}\right)=\Psi
\end{array}
$$

where $\Psi$ is diagonal. This orthogonal model implies the following covariance structure for $\left(r_{t}-\mu\right)$ :

$$
\Sigma=L^{\prime} L+\Psi
$$

To estimate the elements of $L$, the method of principal component analysis is used. Spectral decomposition allows us to express the covariance matrix $\Sigma$ as:

$$
\Sigma=\Lambda_{1,1} e_{1} e_{1}^{\prime}+\ldots+\Lambda_{N M, N M} e_{N M} e_{N M}^{\prime}
$$

where $\Lambda_{1,1}>\ldots>\Lambda_{N M, N M}$ are the ordered eigenvalues and $e_{1}, e_{2}, \ldots, e_{N M}$ are the associated normalized eigenvectors such that $e_{m} e_{m}^{\prime}=1$. As we want to explain the covariance structure in terms of $K<N M$ factors we reduce the above decomposition to:

$$
\begin{aligned}
\Sigma & =\left(\Lambda_{1,1} e_{1} e_{1}^{\prime}+\ldots+\Lambda_{K, K} e_{K} e_{K}^{\prime}\right)+\left(\Lambda_{K+1, K+1} e_{K+1} e_{K+1}^{\prime}+\ldots+\Lambda_{N M, N M} e_{N M} e_{N M}^{\prime}\right) \\
& =\left[\begin{array}{lll}
\sqrt{\Lambda_{1,1}} e_{1} & \cdots & \sqrt{\Lambda_{K, K}} e_{K}
\end{array}\right] \cdot\left[\begin{array}{c}
\sqrt{\Lambda_{1,1}} e_{1}^{\prime} \\
\vdots \\
\sqrt{\Lambda_{K, K}} e_{K}^{\prime}
\end{array}\right]+\left[\begin{array}{ccc}
\psi_{1} & 0 & 0 \\
0 & \ddots & 0 \\
0 & 0 & \psi_{N M}
\end{array}\right] \\
& =L^{\prime} L+\Psi
\end{aligned}
$$

where it is assumed that $\Psi=\Sigma-L^{\prime} L$, which is obtained by setting the off-diagonal elements to zero. ${ }^{13}$ This methodology to obtain estimates of $L$ and $\Psi$, applied to the sample covariance matrix $\widehat{\Sigma}$ is known as the ordinary principal component analysis, as the factor loadings are in fact scaled coefficients of the first $K$ principal components. Basilevsky (1994) shows that the ordinary principal component solution is upward biased. Therefore one has to multiply the solution by a scale factor $\sqrt{\frac{\Lambda_{k, k}-\sigma^{2}}{\Lambda_{k, k}}}$. When the residual variance turns out to be small, these scale factors will only be slightly smaller than one. The complete solution for the factor loadings is then:

$$
L=\left[\begin{array}{lll}
\sqrt{\Lambda_{1,1}} e_{1} \cdot \sqrt{\frac{\Lambda_{1,1}-\sigma^{2}}{\Lambda_{1,1}}} & \cdots & \sqrt{\Lambda_{K, K}} e_{K} \cdot \sqrt{\frac{\Lambda_{K, K}-\sigma^{2}}{\Lambda_{K, K}}}
\end{array}\right]
$$

\footnotetext{
${ }^{13}$ When the off-diagonal elements are not close to zero, this may indicate ommited factors (see Bliss (1997)).
} 
Now that we have defined the factor loadings $L$ and the variance of the specific components $\Psi$ we can generate estimates of the values for the latent factors $F_{t}$ using a simple OLS procedure $^{14}$ :

$$
\begin{aligned}
F_{t} & =\left(L L^{\prime}\right)^{-1} L\left(r_{t}-\mu\right) \\
& =\left[\begin{array}{c}
\frac{1}{\sqrt{\Lambda_{1,1}}} e_{1}^{\prime}\left(r_{t}-\mu\right) \\
\vdots \\
\frac{1}{\sqrt{\Lambda_{K, K}}} e_{K}^{\prime}\left(r_{t}-\mu\right)
\end{array}\right]
\end{aligned}
$$

\footnotetext{
${ }^{14}$ It is assumed that $\Psi$ is homoskedastic.
} 


\section{B Uncentered $\mathbf{R}^{2}$ per Country per Return}

Table 8: Detrended $\mathbf{R}^{2}$ (in \%)

\begin{tabular}{|c|c|c|c|c|c|c|c|c|c|}
\hline \multicolumn{10}{|c|}{ PORTFOLIO } \\
\hline \multicolumn{2}{|c|}{ DEM-USD } & \multicolumn{2}{|c|}{ 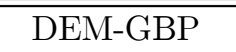 } & \multicolumn{2}{|c|}{ 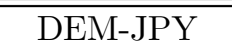 } & \multicolumn{2}{|c|}{ 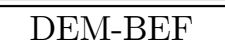 } & \multicolumn{2}{|c|}{ DEM-NLG } \\
\hline$r b_{d e m}^{d e m}$ & 1.79 & $r b_{d e m}^{d e m}$ & 6.10 & $r b_{d e m}^{d e m}$ & 1.31 & $r b_{d e m}^{d e m}$ & 85.33 & $r b_{d e m}^{d e m}$ & 97.80 \\
\hline$r s_{\text {dem }}^{\text {dem }}$ & 95.15 & $r s_{d e m}^{\text {dem }}$ & 95.16 & $r s_{\text {dem }}^{\text {dem }}$ & 94.30 & $r s_{\text {dem }}^{\text {dem }}$ & 99.21 & $r s_{\text {dem }}^{\text {dem }}$ & 99.95 \\
\hline$r b_{u s d}^{d e m}$ & 64.44 & $r b_{g b p}^{d e m}$ & 58.63 & $r b_{j p y}^{d e m}$ & 78.68 & $r b_{b e f}^{\text {dem }}$ & 77.23 & $r b_{n \lg }^{\text {dem }}$ & 97.43 \\
\hline$r s_{u s d}^{d e m}$ & 94.63 & $r s_{g b p}^{\text {dem }}$ & 93.58 & $r s_{j p y}^{\text {dem }}$ & 96.92 & $r s_{\text {bef }}^{\text {dem }}$ & 99.04 & $r s_{n \mathrm{lg}}^{\text {dem }}$ & 99.93 \\
\hline$r b_{d e m}^{u s d}$ & 79.19 & $r b_{d e m}^{g b p}$ & 69.28 & $r b_{d e m}^{j p y}$ & 76.10 & $r b_{d e m}^{b e f f}$ & 68.48 & $r b_{d e m}^{n \lg }$ & 97.61 \\
\hline$r s_{d e m}^{u s d}$ & 95.22 & $r s_{d e m}^{g b p}$ & 95.27 & $r s_{d e m}^{j p y}$ & 95.15 & $r s_{d e m}^{b e f}$ & 99.27 & $r s_{d e m}^{n \lg }$ & 99.95 \\
\hline$r b_{u s d}^{u s d}$ & 7.22 & $r b_{g b p}^{g b p}$ & 1.51 & $r b_{j p y}^{j p y}$ & 1.51 & $r b_{b e f}^{b e f}$ & 88.41 & $r b_{n \lg }^{n \lg }$ & 97.63 \\
\hline$r s_{u s d}^{u s d}$ & 91.38 & $r s_{g b p}^{g b p}$ & 91.60 & $r s_{j p y}^{j p y}$ & 95.11 & $r s_{b e f}^{b e f}$ & 98.91 & $r s_{n \lg }^{n \lg }$ & 99.93 \\
\hline \multicolumn{10}{|c|}{ PORTFOLIO } \\
\hline \multicolumn{2}{|c|}{ DEM-FRF } & \multicolumn{2}{|c|}{ DEM-ATS } & \multicolumn{2}{|c|}{ 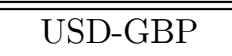 } & \multicolumn{2}{|c|}{ USD-JPY } & \multicolumn{2}{|c|}{$\begin{array}{l}\text { USD-BEF } \\
\end{array}$} \\
\hline$r b_{d e m}^{d e m}$ & 85.79 & $r b_{d e m}^{d e m}$ & 95.30 & $r b_{u s d}^{u s d}$ & 1.96 & $r b_{u s d}^{u s d}$ & 7.07 & $r b_{u s d}^{u s d}$ & 8.09 \\
\hline$r s_{d e m}^{d e m}$ & 99.12 & $r s_{\text {dem }}^{\text {dem }}$ & 99.91 & $r s_{\text {usd }}^{\text {usd }}$ & 88.11 & $r s_{\text {usd }}^{\text {usd }}$ & 90.07 & $r s_{\text {usd }}^{\text {usd }}$ & 91.57 \\
\hline$r b_{f r f}^{d e m}$ & 76.49 & $r b_{a t s}^{d e m}$ & 92.53 & $r b_{g b p}^{u s d}$ & 75.21 & $r b_{j p y}^{u s d}$ & 83.08 & $r b_{b e f}^{u s d}$ & 78.06 \\
\hline$r s_{f r f}^{\text {dem }}$ & 99.00 & $r s_{\text {ats }}^{\text {dem }}$ & 99.93 & $r s_{g b p}^{u s d}$ & 93.04 & $r s_{j p y}^{u s d}$ & 96.36 & $r s_{b e f}^{u s d}$ & 95.06 \\
\hline$r b_{d e m}^{f r f}$ & 69.37 & $r b_{d e m}^{a t s}$ & 95.62 & $r b_{u s d}^{g b p}$ & 59.22 & $r b_{u s d}^{j p y}$ & 74.49 & $r b_{u s d}^{b e f}$ & 69.50 \\
\hline frf & 99.12 & $r s_{\text {dem }}^{a t s}$ & 99.91 & $r s_{u s d}^{g b p}$ & 91.89 & $r s_{u s d}^{j p y}$ & 95.15 & $r s_{u s d}^{b e f}$ & 94.98 \\
\hline$r b_{f r f}^{f r f}$ & 89.24 & $r b_{\text {ats }}^{a t s}$ & 91.97 & $r b_{g b p}^{g b p}$ & 5.98 & $r b_{j p y}^{j p y}$ & 6.29 & $r b_{b e f}^{b e f}$ & 3.41 \\
\hline$r s_{f r f}^{f r f}$ & 98.94 & $r s_{\text {ats }}^{\text {ats }}$ & 99.93 & $r s_{g b p}^{g b p}$ & 90.12 & $r s_{j p y}^{j p y}$ & 94.07 & $r s_{\text {bef }}^{b e f}$ & 94.14 \\
\hline \multicolumn{10}{|c|}{ PORTFOLIO } \\
\hline \multicolumn{2}{|c|}{ "USD-NLG } & \multicolumn{2}{|c|}{ "USD-FRF } & \multicolumn{2}{|c|}{ "USD-ATS } & & & & \\
\hline$r b_{u s d}^{u s d}$ & 6.94 & $r b_{u s d}^{u s d}$ & 7.50 & $r b_{u s d}^{u s d}$ & 6.58 & & & & \\
\hline$r s_{u s d}^{u s d}$ & 91.79 & $r s_{u s d}^{u s d}$ & 90.93 & $r s_{u s d}^{u s d}$ & 91.76 & & & & \\
\hline$r b_{b e f}^{\text {usd }}$ & 79.05 & $r b_{f r f}^{u s d}$ & 76.80 & $r b_{\text {ats }}^{\text {usd }}$ & 80.12 & & & & \\
\hline$r s_{b e f}^{u s d}$ & 93.98 & $r s_{f r f}^{u s d}$ & 95.60 & $r s_{\text {ats }}^{u s d}$ & 97.02 & & & & \\
\hline$r b_{u s d}^{b e f}$ & 66.75 & $r b_{u s d}^{f r f}$ & 61.80 & $r b_{u s d}^{a t s}$ & 70.15 & & & & \\
\hline$r s_{\text {usd }}^{b e f}$ & 95.03 & & 94.42 & $r s_{\text {usd }}^{\text {ats }}$ & 94.95 & & & & \\
\hline$r b_{b e f}^{b e f}$ & 1.05 & $r b_{f_{r} f f}^{f r f}$ & 3.17 & $r b_{a t s}^{a t s}$ & 3.07 & & & & \\
\hline$r s_{\text {bef }}^{\text {bef }}$ & 93.84 & $r s_{f r f}^{f r f}$ & 94.91 & $r s_{\text {ats }}^{a t s}$ & 96.57 & & & & \\
\hline
\end{tabular}




\section{Pricing Errors DEM Benchmark Portfolio \\ C.1 Foreign Viewpoints}
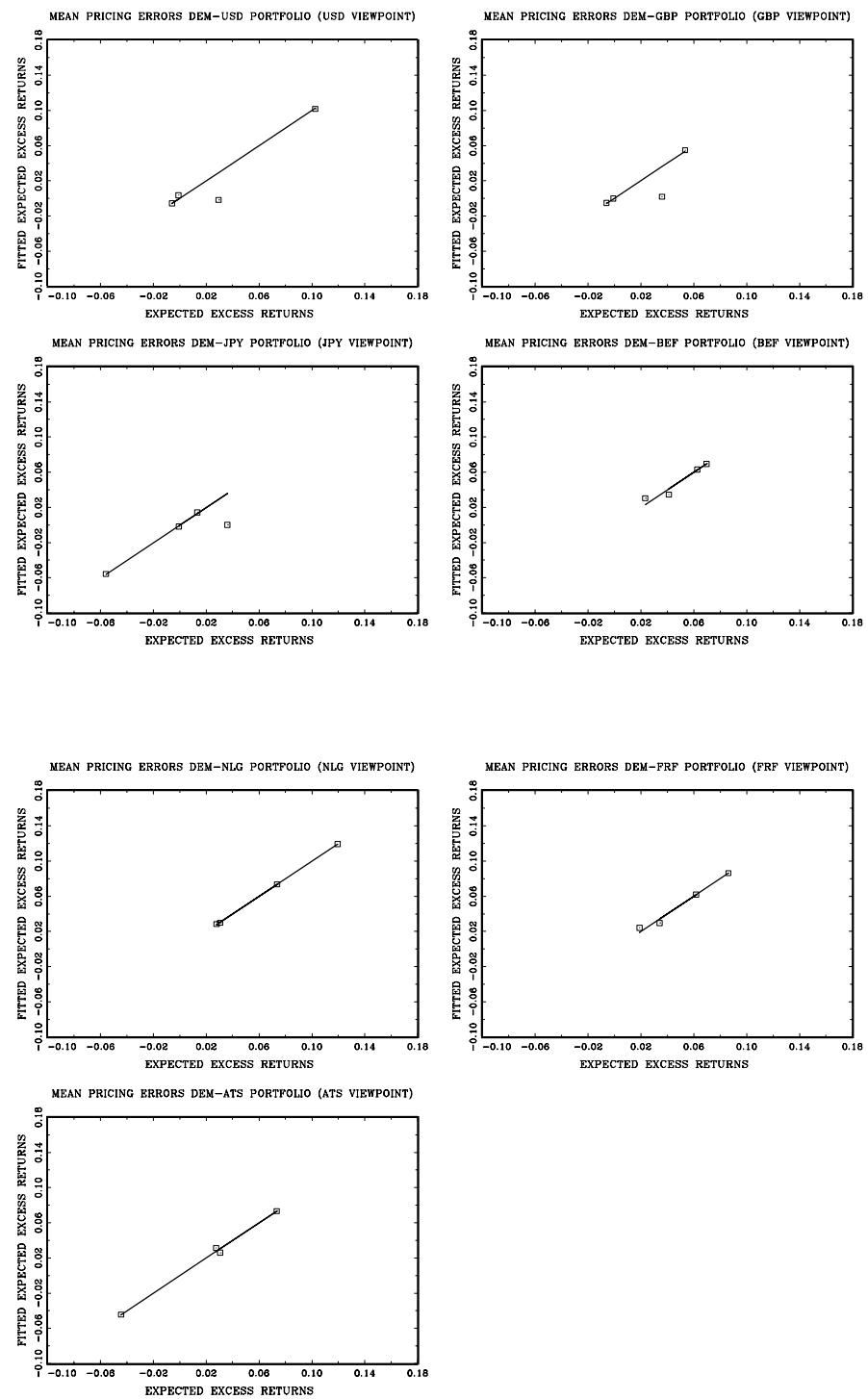

Figure 3: Pricing Errors DEM Benchmark Portfolio (Foreign Viewpoint) 


\section{C.2 Joint Viewpoints}
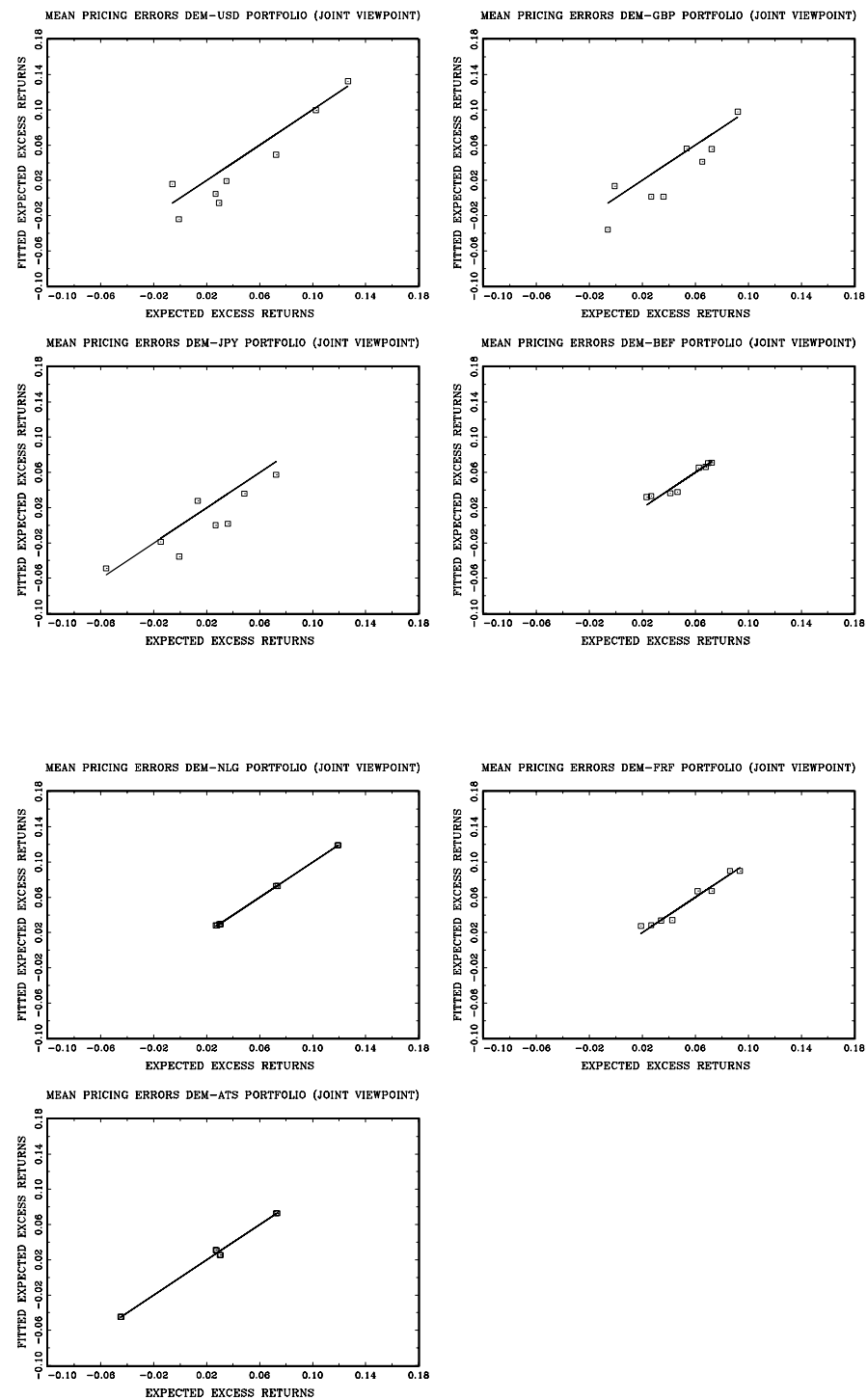

Figure 4: Pricing Errors DEM Benchmark Portfolio (Joint Viewpoint) 


\section{Pricing Errors USD Benchmark Portfolio \\ D.1 Foreign Viewpoints}
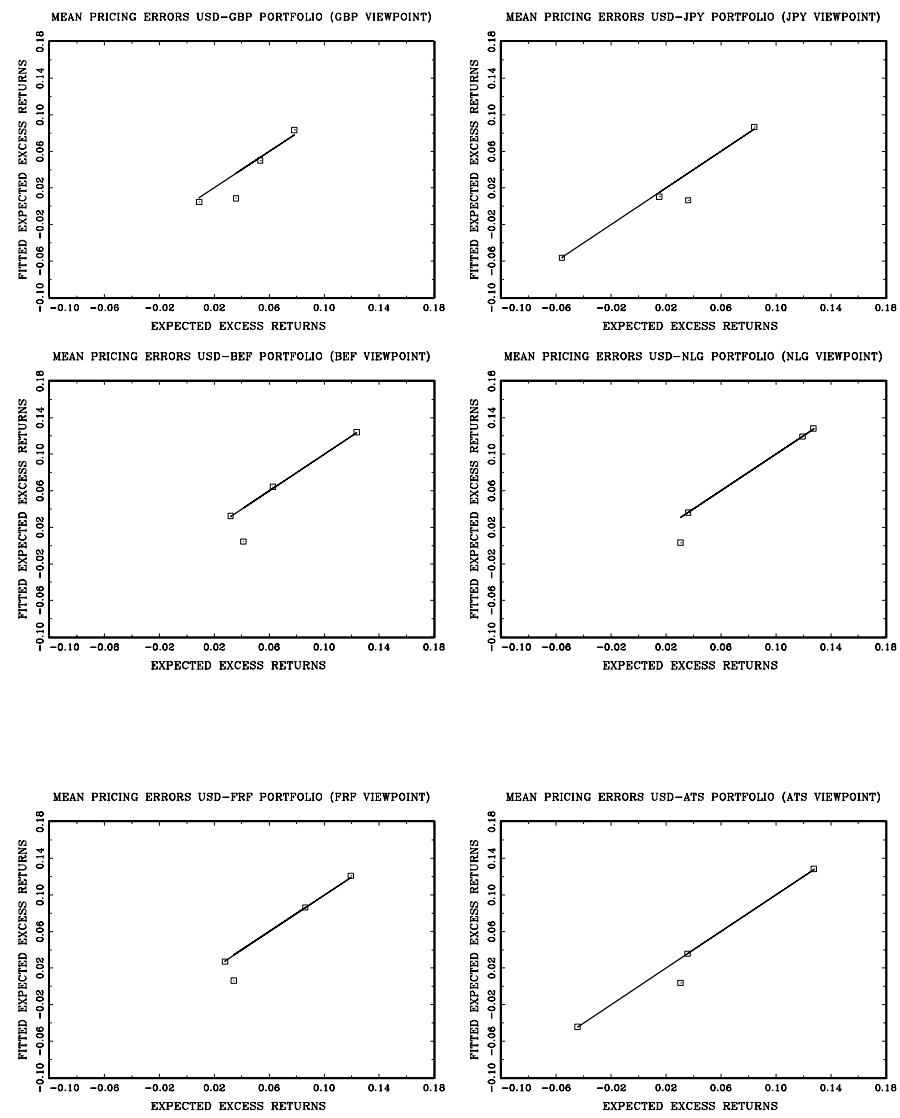

Figure 5: Pricing Errors USD Benchmark Portfolio (Foreign Viewpoint) 


\section{D.2 Joint Viewpoints}
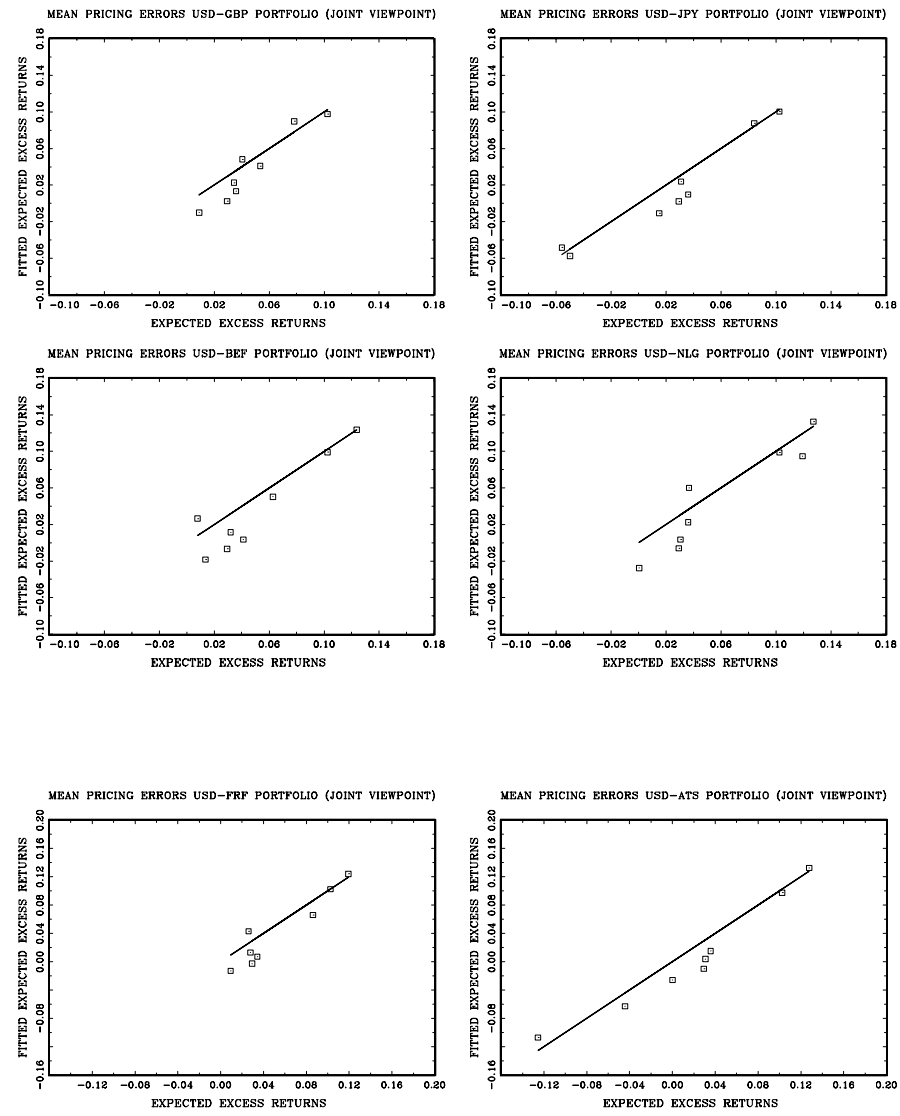

Figure 6: Pricing Errors USD Benchmark Portfolio (Joint Viewpoint) 
E Stochastic Discount Factor Comparison for DEM benchmark Portfolios
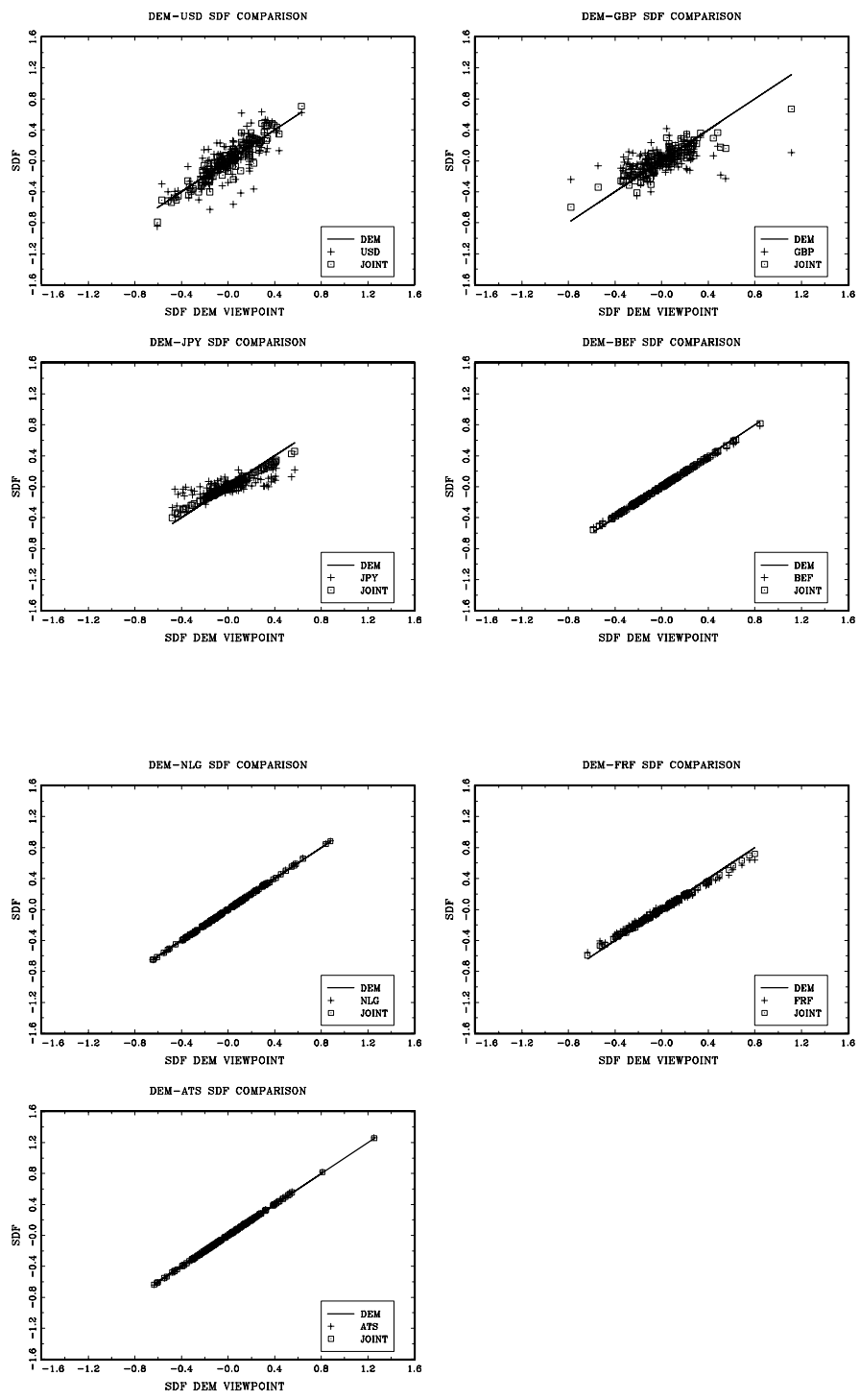

Figure 7: SDF Comparison Across Viewpoints 
F Stochastic Discount Factor Comparison for USD benchmark Portfolios
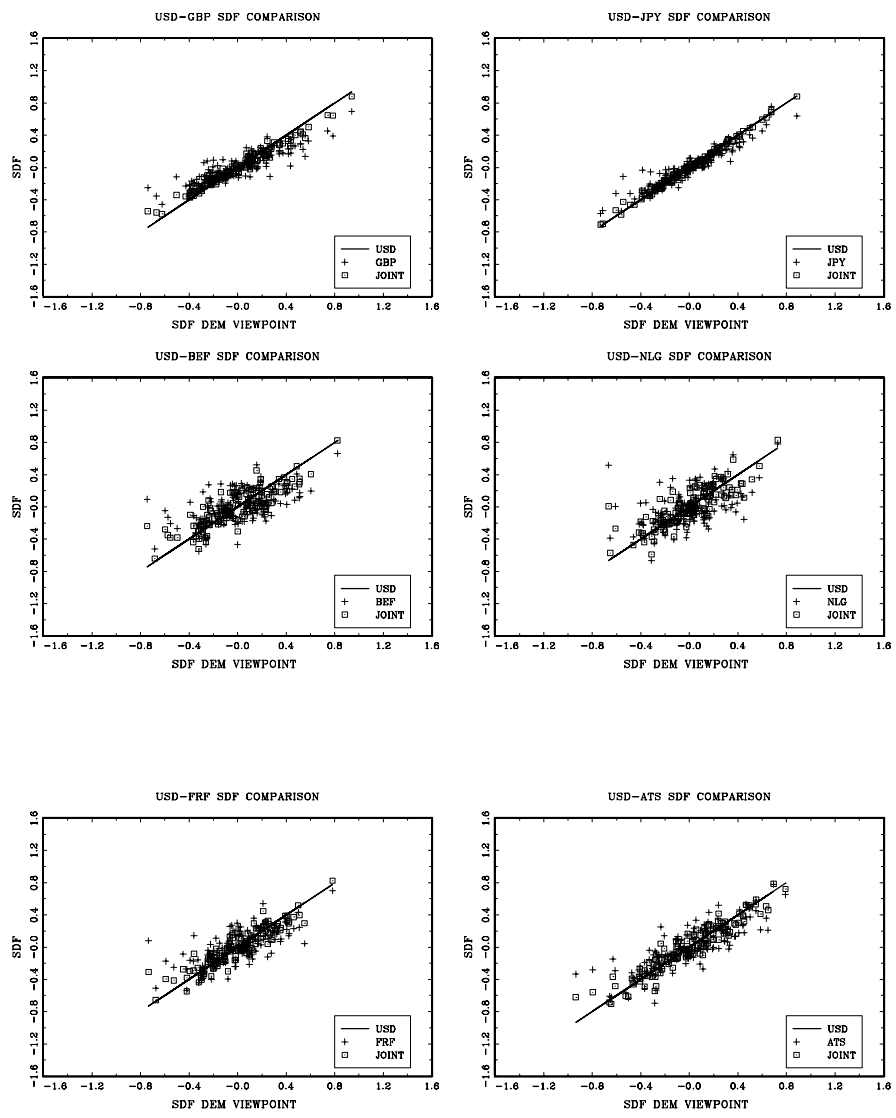

Figure 8: SDF Comparison Across Viewpoints 